\title{
REVIEWS
}

\section{Architecture of Multi-Component Copolymer Brushes: Synthesis, Solution Properties and Application for Nanodevices}

\author{
Koji ISHIZU ${ }^{\dagger}$ \\ Department of Organic Materials and Macromolecules, International Research Center of Macromolecular Science, \\ Tokyo Institute of Technology, 2-12-1-H-133, Ookayama, Meguro-ku, Tokyo 152-8552, Japan
}

(Received June 21, 2004; Accepted June 21, 2004; Published October 15, 2004)

\begin{abstract}
In this review article, we describe the architecture of multi-component copolymer brushes. These copolymer brushes can be classified into tree types, i.e., double-cylinder-type, prototype, and block-type. Double-cylinder-type copolymer brushes were prepared by free-radical polymerization of corresponding diblock macromonomer or by the "grafting from" approach using atom transfer radical polymerization (ATRP). Alternating free-radical copolymerization of the mixture of two macromonomers provided prototype copolymer brushes. ATRP was applied to the synthesis of AB-type brush-block-brush (block-type) copolymers. All copolymer brushes were molecularly dissolved in a dilute solution due to densely branched side chains and took geometrically anisotropic conformation such as cylinder with increasing aspect ratio. In self-assembly process of amphiphilic prototype copolymer brushes in water, hierarchical generations from small rods to large rods were observed, because copolymer brushes exhibited phase-separated hydrophobic/hydrophilic domains. Moreover, binding of anionic/nonionic polyeletrolyte prototype brushes with cationic linear polyelectrolyte formed an interesting complex of a high order by electrostatic interaction. On the other hand, the molecular wires in electronic nanodevices were prepared by forming conducting polypyrroles with an internal core of double-cylider-type copolymer brushes as templates, where as the outer cylinder parts play the role of an insulator. [DOI 10.1295/polymj.36.775]

KEY WORDS Multi-component Copolymer Brush / Double-cylinder-type / Prototype / Blocktype / Macromonomer / ATRP / Aternating Copolymerization / Molecular Wire / Binding /
\end{abstract}

Nanostructured polymers are of rapidly growing interest because of their sized-coupled properties. Generally, the branched polymer has a smaller hydrodynamic dimension than a linear polymer with the same molecular weight. The interest in branched polymers arises from their compactness and their enhanced segment density. Recently, a new class of branched architectural polymers, such as nanocylinders, is attracting attention with expectation that their unique structures may result in unusual properties. It is well known that comb polymers with densely grafted side chains in a good solvent can adopt a worm-like cylinder brush conformations, in which the side chains are stretched in the direction normal to the backbone, owing to the excluded-volume interaction. The polymerization of macromonomers provides regular multi-branched polymers with dense branching. Since both the degree of polymerization $\left(\mathrm{DP}_{n}\right)$ and the length of branches are varied, poly(macromonomer)s, often so-called "polymer brushes", are interesting models for the study of branched polymers. ${ }^{1-9}$ More recently, we have systematically investigated the architecture of multi-component copolymer brushes. Figure 1 shows the illustration of three types of multi-component copolymer brushes. Various strategies

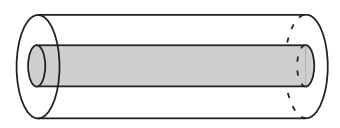

(a) Double-cylinder-type

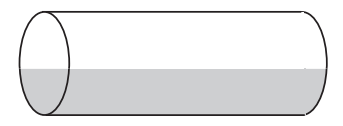

(b) Prototype

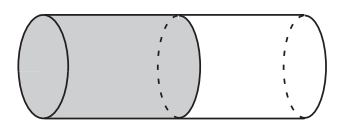

(c) Block-type

Figure 1. Illustration of multi-component copolymer brushes.

can be designed to construct such structures. For example, one strategies for the construction of doublecylinder-type copolymer brushes is based on the self-assembly of block copolymers in the bulk. Depending on their composition, they can form cylindrical morphology in the bulk film. Selective cross-link-

${ }^{\dagger}$ To whom correspondence should be addressed (E-mail: kishizu@polymer.titech.ac.jp). 
ing of the cylindrical domains and redissolution leads to nanoscopic cylinders. This approach was used by Ishizu et al. in order to synthesize rod-like macromolecules with poly(4-vinylpyridine) (P4VP) internal cylinder and polystyrene (PS) external cylinder. ${ }^{10-12}$ The segregated P4VP cylindrical domains were cross-linked using 1,4-dibromobutane (DBB) vapor in the solid state. However, these preparation methods could not control the major length of rod polymers. To overcome these problems, we should employ another strategy to form double-cylinder-type copolymer brushes. Free-radical polymerization of diblock macromonomers or the "grafting from" approach using atom transfer radical polymerization (ATRP) is one of the best methods for the architecture of double-cylinder-type copolymer brushes. Alternating copolymerization of the mixture of two macromonomers is elegant approach for the architecture of prototype copolymer brushes. The construction of block-type copolymer brushes is not so easy. ATRP techniques only provide up to now such phase-separated structures.

In the present review, we report the recent results on the synthesis and solution properties of various types of two-component copolymer brushes where the separation plane is parallel to the cylinder axis. We also describe the application of copolymer brushes for nanodevices.

\section{PROTOTYPE COPOLYMER BRUSHES}

Free-radical copolymerization of binary macromonomers will form copolymers with comb-shaped structure. In the preparation process, the relevant copolymerization parameters are very important in determining the branch distribution in the resulting comb-shaped copolymers. Free-radical copolymerizations of binary vinylbenzyl-terminated PS and polyisoprene (PI) macromonomers were carried out in benzene, varying the molecular weight of the macromonomers. ${ }^{13}$ The reactivity ratios of these systems were close to an azeotropic copolymerization, in the case of the same degree of polymerization $\left(\mathrm{DP}_{n}\right)$ of binary macromonomers. Subsequently, free-radical copolymerizations of vinylbenzyl-terminated PS (PSVB; $M_{1}$ ) and maleate-terminated poly(ethylene oxide) (PEO) macromonomers $\left(\mathrm{M}_{2}\right)$ were carried out in benzene, in order to achieve alternate reactivity. ${ }^{14}$ The reactivity ratios $\left(r_{1}=0.765\right.$ and $\left.r_{2}=0.064\right)$ obtained for the binary macromonomer system were different from corresponding model systems of styrene and maleic acid ethyl ester $\left(r_{1}=0.13\right.$ and $\left.r_{2}=0.035\right)$ due to phase separation. More recently, free-radical copolymerizations of PS-VB $\left(M_{1}\right)$ and methacryloylterminated PEO (PEO-MC; $M_{2}$ ) were carried out in various solvents (benzene, 1,4-dioxane and $\mathrm{N}, \mathrm{N}$-dimethylformamide). ${ }^{15}$ The reactivity ratios obtained for the binary macromonomer systems were also different from corresponding model system of styrene and methyl methacrylate (MMA) $\left(r_{1}=0.52\right.$ and $r_{2}=$ $0.46)$ due to phase separation. PEO macromonomers could not interpenetrate sufficiently into propagating copolymer chains that had radical sites due to phase separation. On the other hand, the reactivity ratios $\left(r_{1}=0.25\right.$ and $\left.r_{2}=0.02\right)$ obtained for the binary copolymerization of PS-VB and PEO-MC/tin tetrachloride $\left(\mathrm{SnCl}_{4}\right)$ macromonomers showed strong alternation. It was suggested that alternation results from homopolymerization of 1:1 complexes (PS-VB; donor and $\mathrm{PEO}-\mathrm{MC} / \mathrm{SnCl}_{4}$; acceptor) formed between the donor and acceptor monomers (see Scheme 1).

These alternating copolymer brushes possessing long aspect ratios can be expected to form phase-separated cylindrical domains (prototype), because incompatible alternating PS and PEO side chains align densely on the main chain. Ishizu et al. ${ }^{16}$ have investigated the dilute-solution properties and structural analysis of such alternating copolymer brushes. Figure 2 shows the plot of effective diffusion coefficient $D_{\text {eff }}$ against polymer concentration (in benzene) on copolymer brushes [P1: PS-VB $M_{\mathrm{n}}=5000$, PEOMC $M_{\mathrm{n}}=5100$, degree of (PS/PEO) alternating units $\left(\mathrm{DP}_{n}\right)_{\mathrm{AB}}=150$ and P2: PS-VB $M_{\mathrm{n}}=5800$, PEO-MC

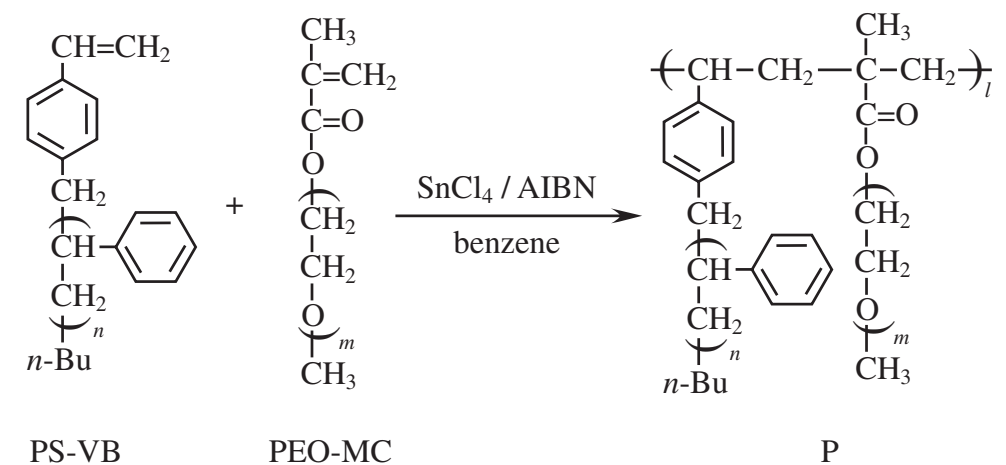

Scheme 1. 


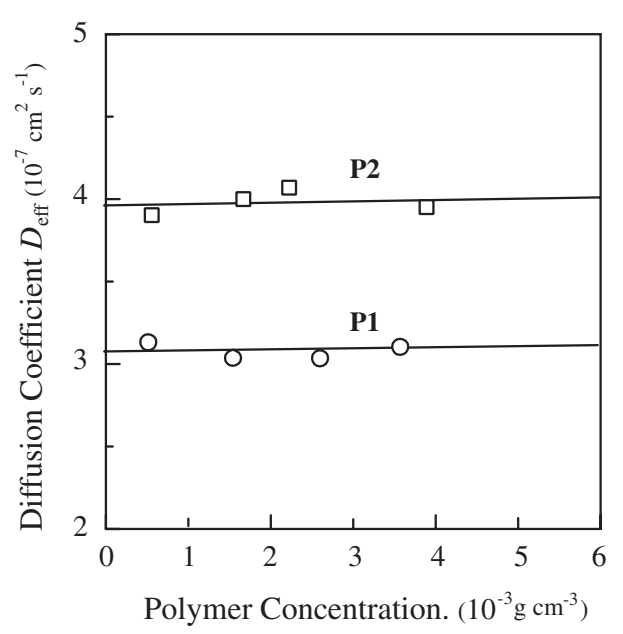

Figure 2. Plot of effective diffusion coefficient $D_{\text {eff }}$ against polymer concentration on $\mathrm{PS} / \mathrm{PEO}$ prototype copolymer brushes $\mathbf{P 1}$ and $\mathbf{P 2}$ in benzene at $25^{\circ} \mathrm{C}$.

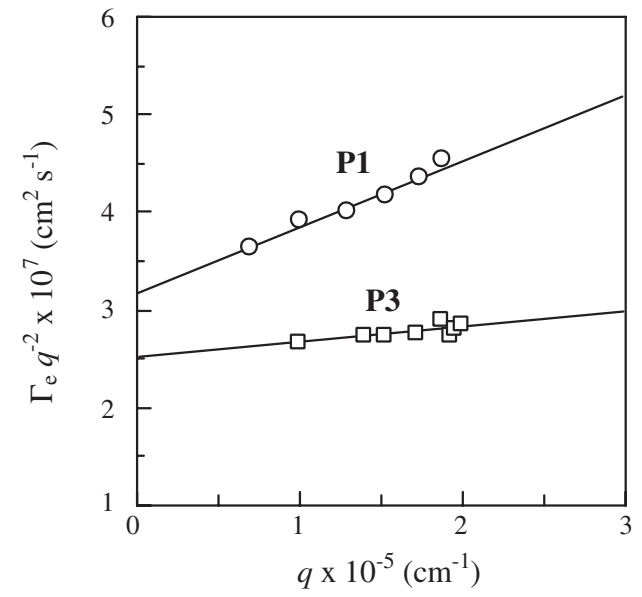

Figure 3. Angular dependence of $\Gamma_{\mathrm{e}} q^{-2}$ for PS/PEO prototype copolymer brushes $\mathbf{P 1}$ and $\mathbf{P 3}$.

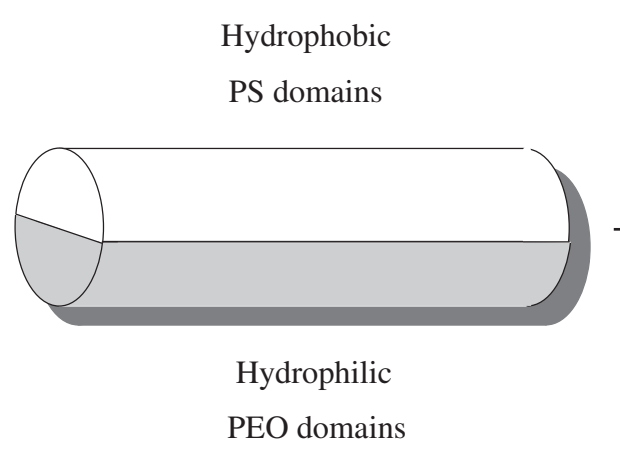

Prototype Copolymer Brush

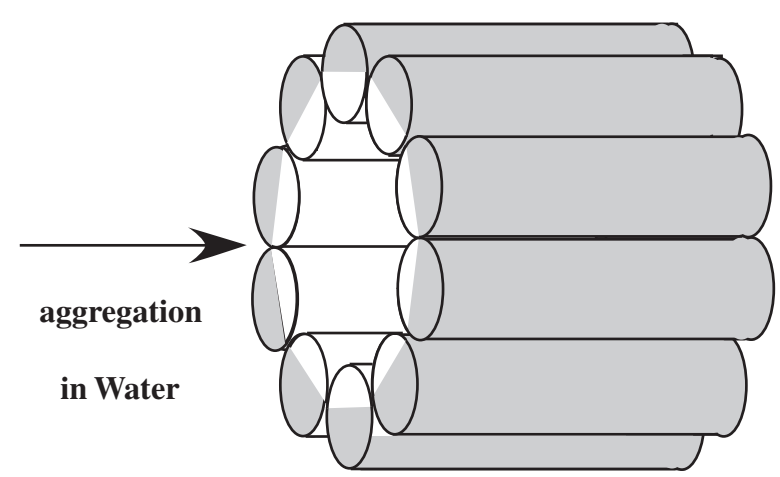

Aggregate of Copolymer Brushes

Figure 4. Illustration for aggregation process of prototype amphiphilic copolymer brushes in water.

$\left.M_{\mathrm{n}}=2100,\left(\mathrm{DP}_{n}\right)_{\mathrm{AB}}=185\right]$. Each $D_{\text {eff }}$ for both copolymer brushes shows the almost constant value in the range of polymer concentrations $(0-6) \times$ $10^{-3} \mathrm{~g} \mathrm{~cm}^{-3}$. These results mean that both copolymer brushes $\mathbf{P 1}$ and $\mathbf{P 2}$ form a unimolecule structure even in good solvent such as benzene. In order to speculate the shape of copolymer brushes P1 and P3 [PS-VB $M_{\mathrm{n}}=1.35 \times 10^{4}$, PEO-MC $M_{\mathrm{n}}=5100,\left(\mathrm{DP}_{n}\right)_{\mathrm{AB}}=$ 16], angular dependence of copolymer brushes $\left(\Gamma_{\mathrm{e}} q^{-2} v s . q ; R_{\mathrm{g}} q \ll 1\right)$ was measured in benzene by dynamic light scattering (DLS), where $\Gamma_{\mathrm{e}}, q$ and $R_{\mathrm{g}}$ indicate the first cumulant, scattering vector and radius of gyration, respectively (Figure 3). Flat slope of this curve means geometrically isotropic shape, i.e., spheres. It is found that the slope of plotted lines $\left(\Gamma_{\mathrm{e}} q^{-2} v s . q\right)$ increases by increasing the aspect ratio of copolymer brushes. Therefore, especially P1 copolymer brush takes geometrically anisotropic conformation such as cylinders in solution.

These alternating amphiphilic copolymer brushes possessing long aspect ratio can be speculated to form some kind of large aggregates as shown in Figure 4. In order to prove the phase-separated cylindrical domains of copolymer brushes, they constructed the large aggregates of copolymer brush P1. Such aggregates were obtained by evaporating tetrahydrofuran (THF) as slowly as possible from homogeneous polymer solution of THF/water mixture. Figure 5 shows scanning electron microscopy (SEM) photograph of aggregates of $\mathbf{P 1}$. Texture shows the existence of large rod-like polymers. Alternating copolymer brush P1 seems to lead self-assemblies among phase-separated hydrophobic PS domains. In this self-assembly process, hierarchical generation, i.e., aggregate formation from small rods to large rods, was observed.

Ishizu's groups have also reported the synthesis and surfactant behavior of prototype amphiphilic copolymer brushes composed of PEO and poly(propylene oxide) (PPO). ${ }^{17}$ Methacryloyl-terminated PPO macromonomer (PPO-MC; $M_{\mathrm{n}}=1200$ ) was synthesized by 


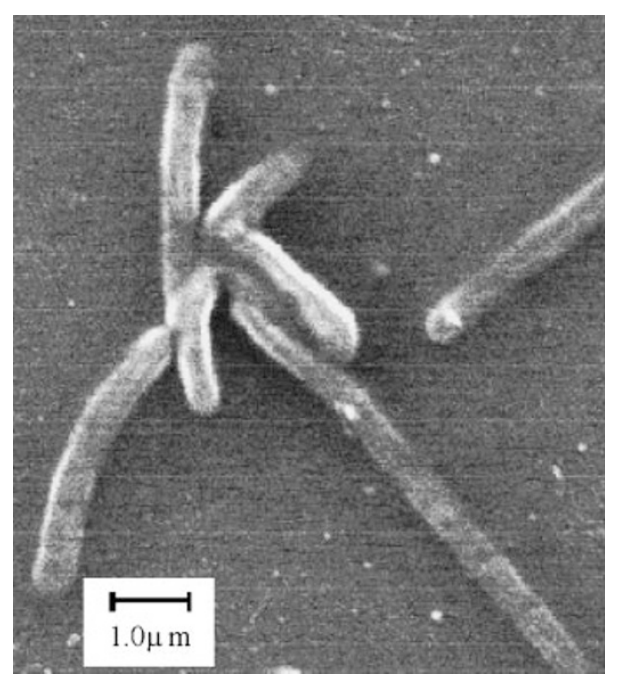

Figure 5. SEM photograph of aggregates of P1. A THF solution of copolymer brush $\left(0.17 \mathrm{mg} \mathrm{mL}^{-1}\right)$ was prepared. Such aggregates were obtained by evaporating THF as slowly as possible (1 week) from a homogeneous polymer solution of a THF/water mixture.

the reaction of commercially available poly(propylene glycol)monobutyl ether with methacryloyl chloride in THF in the addition of triethyl amine as an acid acceptor. Vinylbenzyl-terminated PEO macromonomer $\left(\right.$ PEO-VB; $\left.M_{\mathrm{n}}=2000\right)$ was synthesized under nitrogen by the coupling reaction of commercial poly(ethylene glycol)monomethyl ether by alkoxidation with sodium hydride in toluene followed by reaction with p-chloromethyl styrene (CMS). Well-defined prototype amphiphilic copolymer brushes were prepared by free-radical copolymerizations of PEO-VB with $\mathrm{PPO}-\mathrm{MC} / \mathrm{SnCl}_{4}$ complex in benzene. Unreacted PEO-VB was removed from the copolymerization product with water. Subsequently, unreacted PPOMC was separated from the mixture of copolymer brush and PPO-MC by the precipitation fractionation with a benzene-hexane system. The prototype copolymer brush $\mathbf{P 4}$ obtained was recognized to show unimodal character on the gel permeation chromatography (GPC) profile (polydispersity $M_{\mathrm{w}} / M_{\mathrm{n}}=1.21$ ). The ${ }^{1} \mathrm{H}$ NMR spectrum also supported the formation of prototype copolymer brush; the spectrum displayed the expected resonances for the methyl protons (a: $\delta$ $1.76 \mathrm{ppm}$ ), $-\mathrm{CH}_{2}-\mathrm{CH}-$ protons (b: $3.69 \mathrm{ppm}$ ), and methyl protons of monobutyl ether (c: around 0.72$0.80 \mathrm{ppm}$ ) of PPO chains. Characteristic signals of methylene protons ( $-\mathrm{CH}_{2}-\mathrm{CH}_{2}-\mathrm{O}-$ ) (b: $3.69 \mathrm{ppm}$, this signal overlapped with that of $-\mathrm{CH}_{2}-\mathrm{CH}-$ of PPO chains) and methoxy protons (d: around $3.65 \mathrm{ppm}$ ) of PEO chains were also observed. It was found from the integration ratio of $a$ : $(b-a)$ that PPO and PEO chains copolymerized with 1:1 formula. Table I lists the characteristics and solution properties of amphiphilic copolymer brush P4. The values of the weight-average molecular weight $\left(M_{\mathrm{w}}=1.366 \times\right.$ $\left.10^{-6}\right)$ and radius of gyration $\left(R_{\mathrm{g}}=86.7 \mathrm{~nm}\right)$ of alternating copolymer brush $\mathbf{P 4}$ were derived from a Zimm plot by means of static light scattering (SLS; He-Ne laser $\lambda_{0}=632.8 \mathrm{~nm}$ ) in benzene. The degree of polymerization of alternating $\mathrm{PPO} / \mathrm{PEO}$ units $\left[\left(\mathrm{DP}_{n}\right)_{\mathrm{AB}}=\right.$ 403] can be calculated from the total molecular weight and each arm length of PPO or PEO.

The copolymer brush $\mathbf{P 4}$ also showed a strong angular dependence $\left(\Gamma_{\mathrm{e}} q^{-2} v s . q\right)$ in benzene due to long aspect ratio. Moreover, effective diffusion coefficient $D_{\text {eff }}$ had a constant value in the polymer concentration range $(0-4) \times 10^{-3} \mathrm{~g} \mathrm{~cm}^{-3}$. This suggests that this alternating copolymer brush $\mathbf{P 4}$ forms a unimolecule structure at such polymer concentrations and takes geometrically anisotropic conformation such as cylinders. The translational diffusion coefficient $D_{0}(7.52 \times$ $10^{-8} \mathrm{~cm}^{2} \mathrm{~s}^{-1}$ ) can be estimated by extrapolation of the polymer concentration $C$ to $q$-zero. The hydrodynamic radius $R_{\mathrm{h}}(48.1 \mathrm{~nm})$ is defined by the Stokes-Einstein equation, $R_{\mathrm{h}}=k T / 6 \pi \eta_{0} D_{0}$, where $k, T$, and $\eta_{0}$ indicate the Boltzman constant, the absolute temperature, and the viscosity of the solvent, respectively. The ratio $R_{\mathrm{g}} / R_{\mathrm{h}}$ is a sensitive fingerprint of the inner density profile of macromolecular architectures. This parameter was calculated for various macromolecular architectures. The calculated values of $R_{\mathrm{g}} / R_{\mathrm{h}}$ are 0.775 and $>2$ for hard sphere of uniform density ${ }^{18}$ and for monodisperse rigid rod, ${ }^{19}$ respectively. The obtained value of $R_{\mathrm{g}} / R_{\mathrm{h}}$ (1.80) for prototype copoly-

Table I. Characteristics and solution properties of PPO/PEO prototype copolymer brush ${ }^{\mathrm{a}}$

\begin{tabular}{|c|c|c|c|c|c|c|c|}
\hline \multirow{2}{*}{ Code } & \multicolumn{2}{|c|}{$M_{\mathrm{n}}$ of macromonomers } & \multirow{2}{*}{$10^{-6} M_{\mathrm{w}}^{\mathrm{b}}$} & \multirow{2}{*}{$M_{\mathrm{w}} / M_{\mathrm{n}}{ }^{\mathrm{c}}$} & \multirow{2}{*}{$\left(\mathrm{DP}_{n}\right)_{\mathrm{AB}}{ }^{\mathrm{d}}$} & \multirow{2}{*}{$\begin{array}{c}R_{\mathrm{g}} \mathrm{b} \\
(\mathrm{nm})\end{array}$} & \multirow{2}{*}{$\begin{array}{c}R_{\mathrm{h}}{ }^{\mathrm{e}} \\
(\mathrm{nm})\end{array}$} \\
\hline & PPO-MC & PEO-VB & & & & & \\
\hline P4 & 1200 & 2000 & 1.366 & 1.21 & 403 & 86.7 & 48.1 \\
\hline
\end{tabular}

${ }^{\mathrm{a}}$ Free-radical copolymerization of PEO-VB with $\mathrm{PPO}-\mathrm{MC} / \mathrm{SnCl}_{4}$ complex was carried out in benzene at $60^{\circ} \mathrm{C}$ for $120 \mathrm{~h}$ using AIBN as an initiator; $[\mathrm{PEO}-\mathrm{VB}]_{0}=[\mathrm{PPO}-\mathrm{MC}]_{0}=7.0 \times 10^{-2} \mathrm{~mol} \mathrm{~L}^{-1}, \mathrm{AIBN}=$ $20.0 \times 10^{-2} \mathrm{~mol} \mathrm{~L}^{-1}, \mathrm{SnCl}_{4}=10.5 \times 10^{-2} \mathrm{~mol} \mathrm{~L}^{-1}$. ${ }^{\mathrm{b}}$ Determined by static light scattering (SLS) with Zimm mode in benzene at $25^{\circ} \mathrm{C}$. ${ }^{\mathrm{c}}$ Determined by gel permeation chromatography (GPC) in DMF/0.1 M $\mathrm{LiBr}$ as eluent. ${ }^{\mathrm{d}}$ Degree of polymerization of alternating PPO/PEO units. ${ }^{\mathrm{e}}$ Determined by dynamic light scattering (DLS) wiyh cumulant method in benzene at $25^{\circ} \mathrm{C}$. 


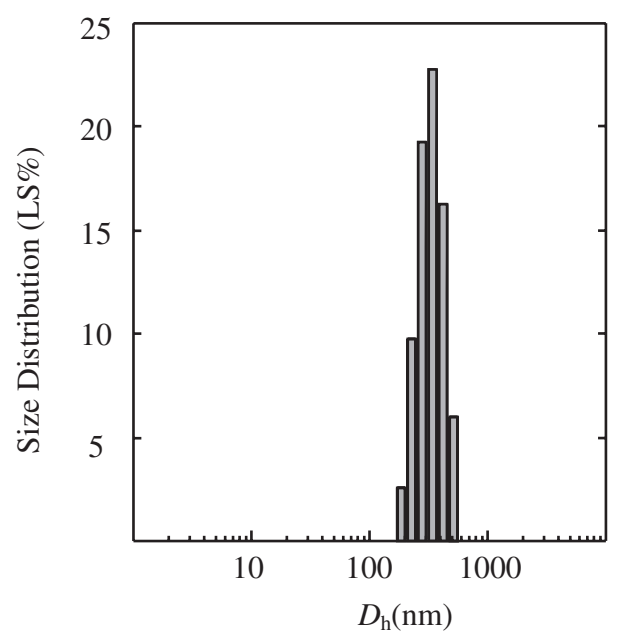

Figure 6. Size distribution profile of the aggregation solution $\left(C=0.001 \mathrm{mg} \mathrm{mL}^{-1}\right)$ of $\mathbf{P 4}$ by DLS with cumulant method.

mer brush P4 is similar to that of the rigid rod model. Therefore, such copolymer brush seems to take rodlike conformation even in a good solvent.

This alternating amphiphilic copolymer brush $\mathbf{P 4}$ can be also speculated to form some kind of large aggregates, because incompatible PPO and PEO side chains form Janus-type phase-separated domains. To explore phase-separated cylinder brush structure, direct observation of aggregates of copolymer brush in an aqueous solution was carried out by SEM. Aqueous solutions of $\mathbf{P 4}$ prepared by varying polymer concentrations $\left(C=0.001-0.1 \mathrm{mg} \mathrm{mL}^{-1}\right)$ exhibited turbidity. However, no precipitates were observed for any of the sample specimens. This means that amphiphilic copolymer brushes formed some kind of aggregate structures.

Figure 6 shows a typical size distribution profile of the aggregate aqueous solution $\left(C=0.001 \mathrm{mg} \mathrm{mL}^{-1}\right)$ of $\mathbf{P 4}$ by DLS with cumulant method. The size distribution profile clearly shows unimodal scattering peak (hydrodynamic diameter $D_{\mathrm{h}}=320 \mathrm{~nm}$ ). On the other hand, a few drops of this aqueous solution were placed onto a glass plate and spin coating was conducted immediately at $3000 \mathrm{rpm}$ for $5 \mathrm{~min}$. The morphology of the aggregates was investigated by the use of field emission gun scanning electron microscopy (FESEM) with a tilt angle of $30^{\circ}$. Figure 7 a shows the FE-SEM photograph of the aggregation product of P4 $\left(C=0.001 \mathrm{mg} \mathrm{mL}^{-1}\right)$. The texture shows the existence of micro-order large rod aggregates (observed values: $\operatorname{rod}$ radius $R=0.22 \pm 0.01 \mu \mathrm{m}$, rod length $L=$ $1.5 \pm 0.2 \mu \mathrm{m})$. It seems that the copolymer brush $\mathbf{P 4}$ self-assembles among hydrophobic PPO domains during evaporation of water. Large rods are stabilized sterically by highly branched hydrophilic PEO brushes in water. Figure $7 \mathrm{~b}$ shows the FE-SEM photograph of the aggregation product of $\mathbf{P 4}\left(C=0.1 \mathrm{mg} \mathrm{mL}^{-1}\right)$.
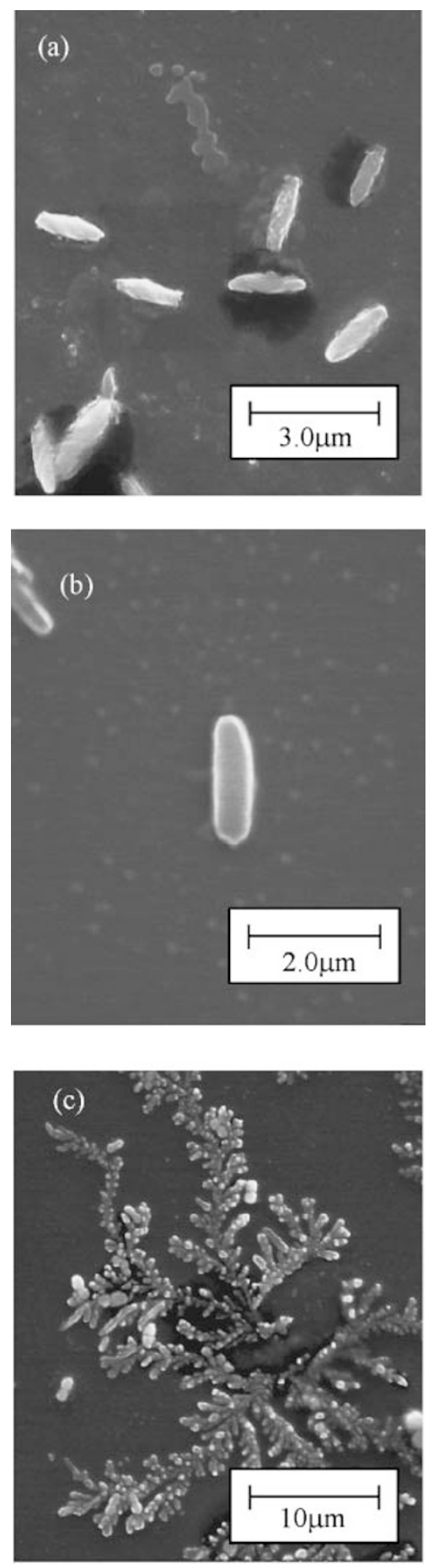

Figure 7. FE-SEM photographs of the aggregation products of P4: (a) aggregation product at $C=0.001 \mathrm{mg} \mathrm{mL}^{-1}$, (b) aggregation product at $C=0.1 \mathrm{mg} \mathrm{mL}^{-1}$, and (c) adhesive aggregates around the glass wall of dish at $C=0.1 \mathrm{mg} \mathrm{mL}^{-1}$.

The texture also shows micro-order large rod aggregates and their sizes are almost identical to those obtained from $C=0.001 \mathrm{mg} \mathrm{mL}^{-1}$ solution. Therefore, these rod aggregates seem stable with the same size in the range of polymer concentration $(C)$ 0.01$0.1 \mathrm{mg} \mathrm{mL}^{-1}$.

On the other hand, Figure 7c shows the FE-SEM photograph of $\mathbf{P 4}\left(C=0.1 \mathrm{mg} \mathrm{mL}^{-1}\right)$ adhesive aggre- 


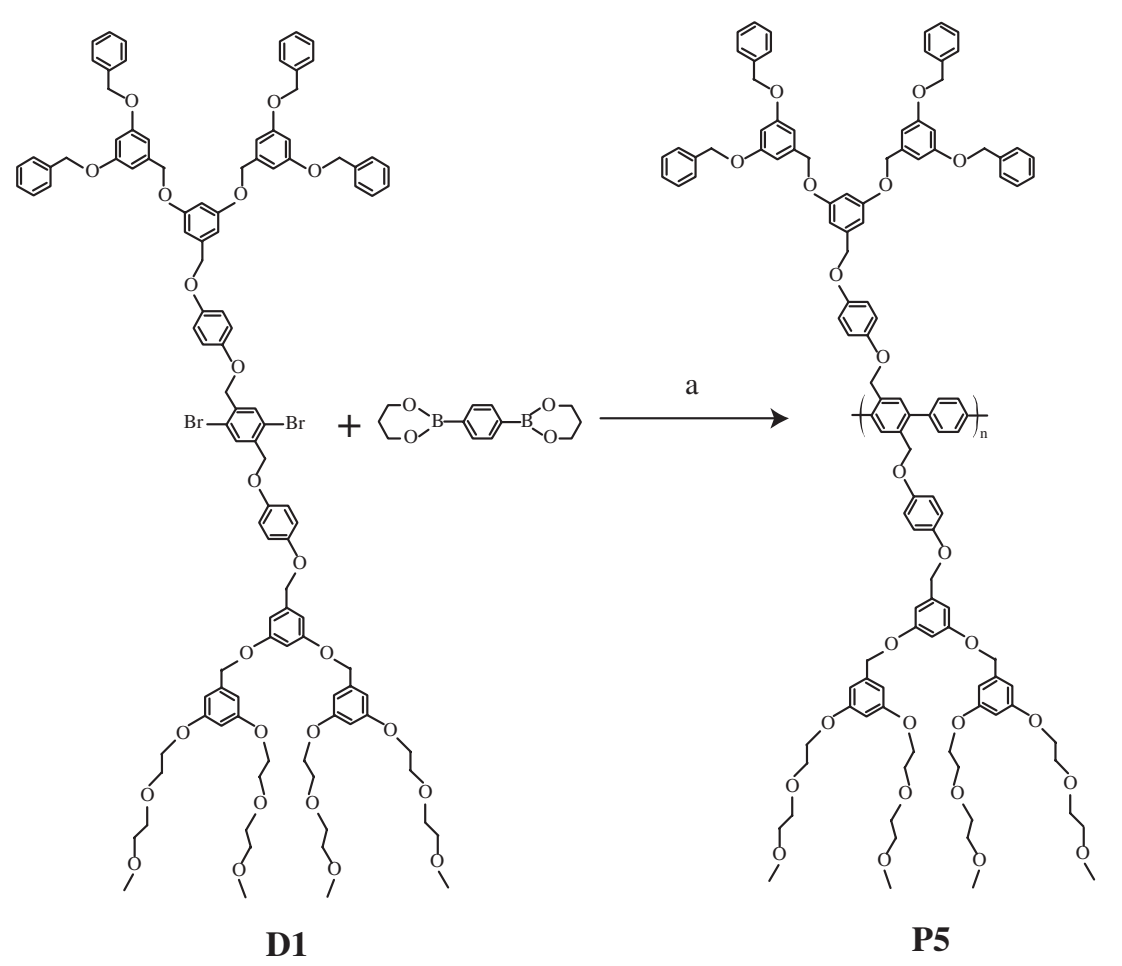

Scheme 2.

gates around the glass wall of the dish employed in the sample preparation. The texture shows interesting morphology such as cascade, i.e., tree-like generation of rods. It seems that the aggregates of copolymer brush $\mathbf{P 4}$ lead to hierarchical generation in the aggregation process. As mentioned earlier, PS/PEO prototype copolymer brushes formed long straight rods with high aspect ratios by two-dimensional (2-D) generation. However, PPO/PEO prototype copolymer brushes formed the cascade aggregates by three-dimensional (3-D) generation. Hydrophobicity for PPO domains is weaker than that for PS domains in water. $\mathrm{PPO} / \mathrm{PEO}$ copolymer brushes may be able to lead the 3-D self-assembly such as supramolecules.

Amphiphilic nanocylinders can be also prepared from another synthetic strategy. Schlüter et al..$^{20}$ have reported the synthesis of the prototype amphiphilic nanocylinder P5 by polycondensation of Suzuki-type dendron D1 with diboronic acid ester under standard conditions $^{21}$ in $2 \mathrm{~N} \mathrm{NaHCO}_{3}$ and THF with $[\operatorname{Pd}\{\mathrm{P}(p-$ tolyl $\left.)_{3}\right\}_{3}$ ] as the catalysis precursor (Scheme 2). They serve a novel and giant consistents of self-aggregated assemblies and should show interesting behavior at interface. Langmuir monolayers of D1 and P5 have been prepared at the air/water interface. Surface pressure-area isotherms at room temperature reveal stable monolayers at pressure of more than $20 \mathrm{mN} \mathrm{m}^{-1}$ (see Figure 8). The monolayers of D1 exhibit very good reversibility for compression, decompression, and repeating cycles, with an area per molecule of about $0.73 \mathrm{~nm}^{2}$ per molecule at $20 \mathrm{mN} \mathrm{m}^{-1}$. This is consis-

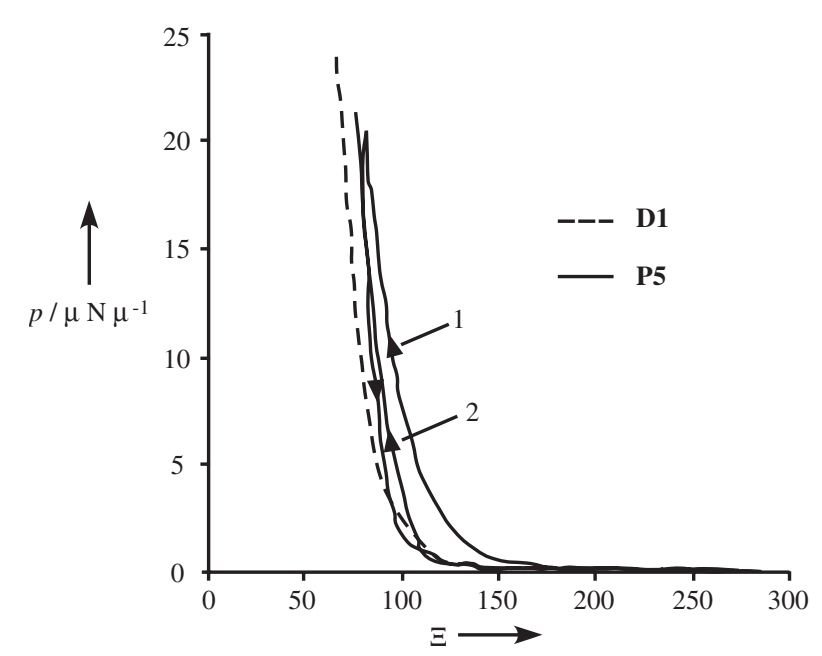

Figure 8. Surface pressure-area of D1 and $\mathbf{P 5}$ at room temperature ( $x$ in $\AA^{2}$ per r.u.: 1 and 2 indicate the first and second compression). Area change is less than $1 \%$ during $20 \mathrm{~min}$.

tent with a monolayer structure in which the four ethyleneoxy chains per water soluble dendron are close packed and oriented perpendicularly to the monolayer, thereby defining a minimum area per molecule. In comparison, $\mathbf{P 5}$ exhibits a 10\% larger area per repeat unit (r.u.) $\left(0.82 \mathrm{~nm}^{2}\right.$ per r.u.) upon the first decompression and a shift to a more reversible isotherm and a smaller area per r.u. in the second cycle $\left(0.77 \mathrm{~nm}^{2}\right.$ per r.u.). The good agreement between the areas per molecule of D1 and per r.u. of P5 indicates a structure of the polymer monolayer in which the rod-like macromolecules are oriented with their long axes within 
Table II. Characteristics and solution properties of PS/PEO prototype copolymer brush ${ }^{\mathrm{a}}$

\begin{tabular}{ccccccccc}
\hline Code & $10^{-6} M_{\mathrm{w}}{ }^{\mathrm{b}}$ & $M_{\mathrm{w}} / M_{\mathrm{n}}{ }^{\mathrm{c}}$ & $F^{\mathrm{d}}$ & $\mathrm{DP}_{n}{ }^{\mathrm{e}}$ & $\begin{array}{c}R_{\mathrm{h}}{ }^{\mathrm{f}} \\
(\mathrm{nm})\end{array}$ & $\begin{array}{c}R_{\mathrm{g}} \mathrm{b} \\
(\mathrm{nm})\end{array}$ & $\begin{array}{c}R_{\mathrm{g}, \mathrm{c}} \mathrm{g} \\
(\mathrm{nm})\end{array}$ & $R_{\mathrm{g}} / R_{\mathrm{h}}$ \\
\hline $\mathbf{P 6}$ & 4.45 & 1.43 & 0.48 & 975 & 14.2 & 30.0 & 6.2 & 2.11 \\
\hline
\end{tabular}

${ }^{\mathrm{a}}$ Macromonomers: PS-VB $M_{\mathrm{n}}=4200$, PEO-MC $M_{\mathrm{n}}=2100 .{ }^{\mathrm{b}}$ Determined by SLS with Zimm mode in benzene at $25^{\circ} \mathrm{C}$. ${ }^{\mathrm{c}}$ Determined by GPC in THF as the eluent at $38^{\circ} \mathrm{C}$. ${ }^{\text {P }} \mathrm{PEO}$ fraction in copolymer brush; deter-

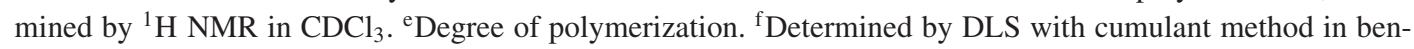
zene at $25^{\circ} \mathrm{C}$. ${ }^{\mathrm{g}}$ Determined by small-angle X-ray scattering (SAXS) using cross-sectional Guinier's plot in benzene.

the monolayer plane and close packed. Moreover, hydrophilic ethyleneoxy chains are on that side of the polymer that faces the water subphase, while the more hydrophobic dendron faces the air side of the polymer.

PS/PEO prototype copolymer brushes can be converted into sulfonated PS (PSS)/PEO brushes (anionic/nonionic polyelectrolyte prototype) by sulfonation. In this section, we mention the results concerning the electrostatic interactions of charged prototype brushes with cationic linear polyelectrolyte [quaternized poly(4-vinylpyridine) (P4VPQ)]. ${ }^{22}$ Table II lists characteristics and solution properties of PS/PEO prototype copolymer brush $\mathbf{P 6}$ used in this work. It was also mentioned in the previous results on DLS that prototype copolymer brush $\mathbf{P 6}$ with high aspect ratio showed strong angular dependence and the translational diffusion coefficient $D(C)$ had a constant value against polymer concentration. The PS/PEO brush P6 was molecularly dissolved in dilute benzene solution. It was mentioned earlier that the ratio $R_{\mathrm{g}} / R_{\mathrm{h}}$ was a sensitive fingerprint of the inner density profile of macromolecular architectures. The observed value of $R_{\mathrm{g}} / R_{\mathrm{h}}$ for PS/PEO brush is 2.11 . Then, this copolymer brush takes a relatively compact shape in a good solvent.

One can consider the molecular size of PS/PEO brush P6 in the solution. Assuming a polydisperse rod-like shape and neglecting $R_{\mathrm{g}, \mathrm{c}}$ (cross-sectional radius of gyration was determined by small-angle $\mathrm{X}$ ray scattering using Guinier's equation: $\ln [I(q) q]=$ const $\left.-(1 / 2)\left(R_{\mathrm{g}, \mathrm{c}}{ }^{2}\right) q^{2}\right), R_{\mathrm{g}}$ is given by the following relation

$$
\begin{aligned}
& R_{\mathrm{g}}=L_{\mathrm{w}} / \sqrt{(5 / 27)} \\
& \text { for the Schulz-Zimm length distribution } \\
& \qquad\left(L_{\mathrm{w}} / L_{\mathrm{n}}=1.5\right)
\end{aligned}
$$

where $L_{\mathrm{w}}$ denotes the length of a rod-like molecule.

Equation 1 allows one to evaluate the rod length as $L_{\mathrm{w}}=69.7 \mathrm{~nm}$. The cross-sectional diameter $d$ is calculated from $R_{\mathrm{g}, \mathrm{c}}$ as

$$
d=(\sqrt{8}) R_{\mathrm{g}, \mathrm{c}}
$$

by assuming a constant electron density across the cylinder. Since eq 2 yields $d=17.5 \mathrm{~nm}$, the aspect ratio $L_{\mathrm{w}} / d$ (3.98) is significantly larger than 2.5 . Accordingly, the shape of the prepared $\mathbf{P 6}$ is much more similar to a cylindrical shape.

Subsequently, the PS/PEO prototype copolymer brush P6 was converted into a sulfonated PS (PSS)/ PEO brush (P6S) by sulfonation using chlorosulfuric acid. The P6S (degree of sulfonation QS $=36.6 \%$ ) was soluble in water. This copolymer brush also showed a strong angular dependence on DLS data in water, and the mutual diffusion coefficient $D(C)$ has an almost constant value $\left(D_{0}=2.67 \times 10^{-8} \mathrm{~cm}^{2} \mathrm{~s}^{-1}\right)$ in the range $0.4-5.6 \mathrm{mg} \mathrm{mL}^{-1}$ of polymer concentration. This suggests that the copolymer brush is molecularly dissolved at such a polymer concentration. The value of $R_{\mathrm{h}}$ was estimated to be $45.7 \mathrm{~nm}$. This value is somewhat larger than that $\left(R_{\mathrm{h}}=14.2 \mathrm{~nm}\right.$, see Table II) for PS/PEO prototype copolymer brush P6 in benzene, even if considering electric double layers by charge effect. Both polymer components (PSS and PEO) are soluble in water. It seems therefore to lead intermolecular cross-linking (formation of $n$-mer of P6S) during sulfonation process.

Next, they studied the binding behaviors of PSS/ PEO prototype brushes to linear P4VPQ (starting material P4VP; $M_{\mathrm{w}}=8 \times 10^{5}$ ) in an aqueous solution, varying the blend ratio and polymer concentration. P4VP (1 wt \% solution) was quaternized with $\mathrm{CH}_{3} \mathrm{I}$ ([4VP unit] $/\left[\mathrm{CH}_{3} \mathrm{I}\right]=1 / 3 \mathrm{~mol} \mathrm{~mol}^{-1}$ ) in ethanol at room temperature for $1 \mathrm{~d}$. The degree of quaternization (DQ) was determined by ${ }^{1} \mathrm{H}$ NMR in DMSO- $d_{6}$ [from the integration ratio of protons $(\delta 8.65$ and $7.35 \mathrm{ppm})$ of the quaternized pyridine ring to protons (8.308.22 and $6.56 \mathrm{ppm}$ ) of pyridine ring]. The DQ value of P4VPQ sample was estimated to be $100 \mathrm{~mol} \%$ under such conditions. When anionic PSS domains of PSS/PEO brush molecules abundantly bind on quaternized 4VP groups (cationic sites), P4VPQ chains should become elongated and brush-P4VPQ complexes take a rod shape, because the cross-sectional diameter of the complex becomes greater. A blend solution $\left(C_{0}=0.005 \mathrm{wt} \%\right)$ of P6S with P4VPQ [P6S/ P4VPQ: 5/1 (w/w)] showed turbidity, but no precipitates were observed. This blend ratio corresponds to a molar ratio of P6S into P4VPQ of ca. 2:1. Figure 9a shows the size distribution of such binding product 
(a)

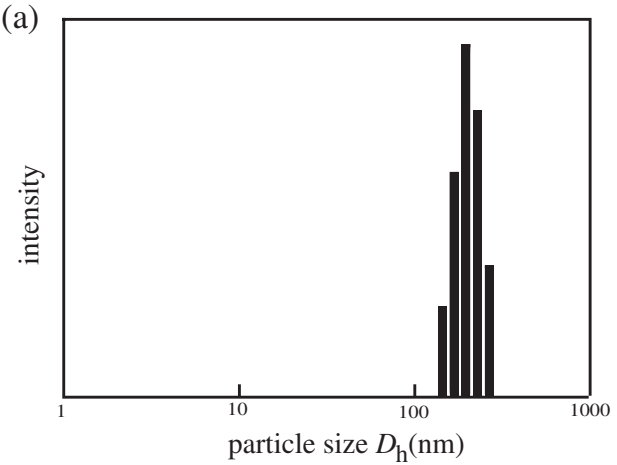

(b)

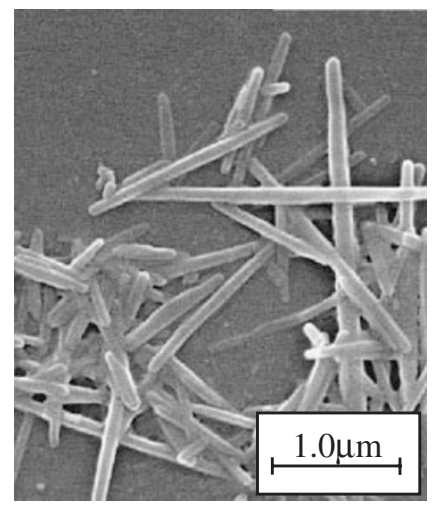

(c)

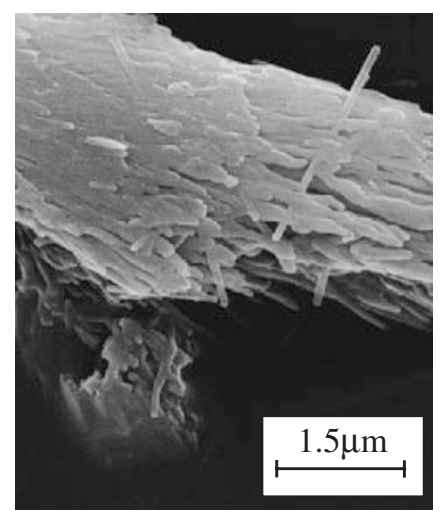

Figure 9. Hydrodynamic diameter distribution of PSS/PEO prototype brush P6S aggregate/P4VPQ complex in water (a) and FE-SEM photograph [prepared from $0.005 \mathrm{wt} \%$ of P6S/ P4VPQ:5/1 (w/w) aqueous solution (b and c).

by means of DLS. Single narrow peak is observed at $D_{\mathrm{h}}=266.1 \mathrm{~nm}$. Parts b and c of Figure 9 show FESEM photographs of the binding product. Textures indicate the flux of large rigid rods or a single rod (diameter $=c a .130 \mathrm{~nm}$ ). This rod diameter is too large, under the assumption that single PSS/PEO brushes bind with P4VPQ by electrostatic interaction. It is reasonable that PSS/PEO brush aggregates bind with P4VPQ molecule. In the illustration of Figure 10, there are several P4VPQ chains inside the aggregates, because the feed molar ratio of P6S into P4VPQ was $2: 1$. It can be therefore speculated that there are several P4VPQ chains inside the aggregates. It is found from both photographs that these semiflexible P4VPQ chains changed to stretched conformation by electrostatic interaction during binding process. The complex formation of P6S with P4VPQ can be speculated as follows. Anionic PSS domains of brush molecules abundantly bind on P4VPQ chains in the first stage: (1) intermolecular aggregation among such complexes (complex 1) and (2) PEO shells lead to fusion with PEO domains of P6S brushes. By repeating these aggregation processes, supermicelles are formed as sketched in Figure 10 (complex 2). In this illustration, authors sketch that PSS is inside and PEO is outside of the aggregated structure. However, it is possible to consider that these large rods are stabilized by highly grafted PSS chains. One can also assume other structures of the complexes: they are coiled in middle of the filament such that the core of the filament consists of a string of many coiled P4VPQ chains. Imae et al. have investigated the binding of poly(amido amine) dendrimer to sodium hyaluronate (NaHA). ${ }^{23}$ They concluded that the structure of NaHA changed to a rod-like one by the electrostatic interaction with dendrimers. The results described above were very similar to Imae's investigations. So, the P4VPQ chains may be stretched by the electrostatic interaction with PSS/ PEO copolymer brushes.

More recently, Schmidt et al. have prepared the statistical copolymer brushes consisting of statistically arranged quaternized P2VP and poly(methyl methacrylate) (PMMA) side chains. ${ }^{24}$ They found the supermolecular structure formation (supermolecular order of a few polymer molecules into filament-like structures) of such statistical copolymer brushes in the solid state due to intramolecular phase separation of PMMA and quaternized P2VP side chains. This recent result qualitatively agrees with the investigation of Ishizu et al. ${ }^{16}$ who postulated fiber formation by prototype copolymer brush with PS and PEO side chains in dilute solution (see the sketch in Figure 4).

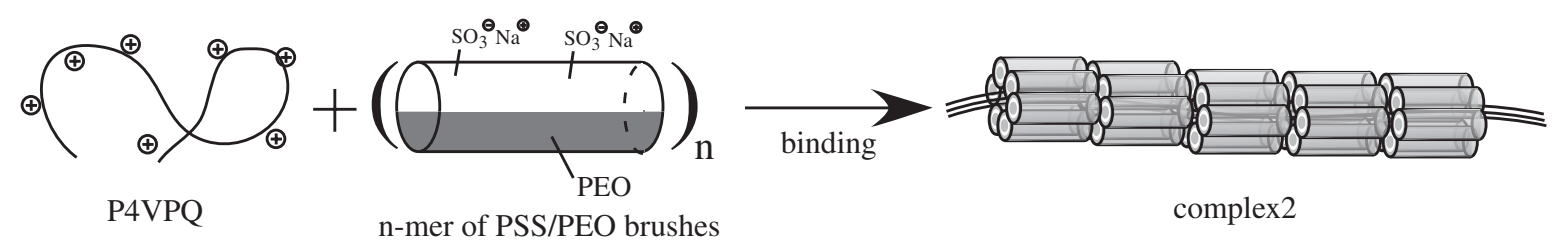

Figure 10. Illustration in binding process of PSS/PEO brush with P4VPQ by electrostatic interaction in water. 


\section{DOUBLE-CYLINDER-TYPE COPOLYMER BRUSHES}

Ishizu et al. have reported the synthesis and dilutesolution properties of poly(diblock macromonomer)s (double-cylinder-type brushes) by free-radical polymerization of the corresponding diblock macromonomer: PS-block-PI ${ }^{25}$ and poly $(\alpha$-methyl styrene) (PMS)-block-P2VP26 double-cylinder-type copolymer brushes. They also prepared such copolymer brushs by anionic one-shot polymerization of $\mathrm{AB}$-type diblock macromonomers. ${ }^{27}$ These types of double-cylinder-type brushes have the advantage of controlling the stiffness of the main chain parts by cross-linking internal PI or P2VP blocks. In fact, they derived the cylinder brushes by cross-linking internal P2VP domains of double-cylinder-type brushes with 1,4-diiodobutane (DIB). ${ }^{26}$ At first, we describe these results as follows.

Vinylbenzyl-terminated PMS-block-P2VP diblock macromonomers $(\mathbf{B})$ were synthesized by the living anionic polymerization technique of the coupling of corresponding diblock lithium with a small excess amount of $p$-chloromethylstyrene (CMS) in tetrahydrofuran (THF) ${ }^{26}$ A typical GPC profile of the $\mathbf{B 2}$ diblock macromonomer is shown in Figure 11. The GPC profile shows a unimodal pattern with a relatively narrow molecular weight distribution $\left(M_{\mathrm{w}} / M_{\mathrm{n}}=\right.$ 1.21). The functionalities of diblock macromonomers (B1-B4) were more than 0.9. Characteristics of the diblock macromonomers $\mathbf{B}$ are listed in Table III. Freeradical polymerizations of $\mathbf{B}$ were carried out in benzene using 2,2'-azobisisobutyronitrile (AIBN) as an initiator at $60^{\circ} \mathrm{C}$. The polymerization conditions and results are listed in Table IV. Figure 11 also shows a typical GPC profile of the polymerization product P15 (starting macromonomer B2) taken with refractive index (RI) and low-angle laser light scattering (LALLS) detectors. The GPC distribution of P15 is bimodal. It can be seen that the polymerization product is a mixture of the copolymer brush and a small amount of unreacted diblock macromonomers. The value of $M_{\mathrm{w}}, M_{\mathrm{w}} / M_{\mathrm{n}}$ and conversion are estimated

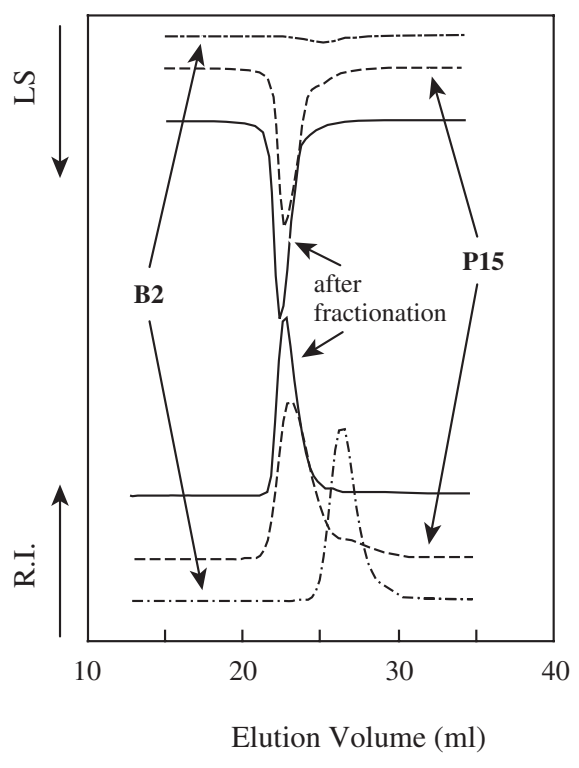

Figure 11. GPC profiles of the diblock macromonomer B2 and the double-cylinder-type copolymer brush P15.

Table III. Characteristic of diblock macromonomers

\begin{tabular}{lcccc}
\hline Code & $M_{\mathrm{n}}{ }^{\mathrm{a}}$ & $M_{\mathrm{w}} / M_{\mathrm{n}}{ }^{\mathrm{b}}$ & $\begin{array}{c}\text { PMS block } \\
(\mathrm{mol} \%)\end{array}$ & Functionality \\
\hline B1 & 2700 & 1.19 & 77 & 0.92 \\
B2 & 2800 & 1.21 & 76 & 0.90 \\
B3 & 2900 & 1.20 & 67 & 0.90 \\
B4 & 7100 & 1.21 & 75 & 0.91 \\
\hline
\end{tabular}

${ }^{a}$ Determined by vapor pressure osmometry (VPO) in benzene. ${ }^{\mathrm{b}}$ Dtermined by GPC. ${ }^{\mathrm{c}}$ Determined by ${ }^{1} \mathrm{H} \mathrm{NMR}$ in $\mathrm{CDCl}_{3}$.

from the GPC chart. The molecular weight distributions $\left(M_{\mathrm{w}} / M_{\mathrm{n}}=1.18-1.28\right)$ of the copolymer brushes became broad with an increment of the $\mathrm{DP}_{n}$. The $\mathrm{DP}_{n}$ of the double-cylinder-type brushes was controlled by the initial concentration of the macromonomer $[\mathrm{M}]_{0}$. The conversions reached more than $80 \%$, in contrast with the results for (PS-block-PI) double-cylindertype brushes (ca. 18.5-40.3\%). ${ }^{25}$ In the preparation of (PS-block-PI) double-cylinder-type brushes, the propagating radicals attacked partially allyl groups of the PI blocks. The polymerization products were

Table IV. Polymerization condition and results of $\mathbf{B} 1^{\mathrm{a}}$

\begin{tabular}{|c|c|c|c|c|c|c|}
\hline \multirow[b]{2}{*}{ Code } & \multicolumn{2}{|c|}{ Feed } & \multicolumn{4}{|c|}{ Coolymer brushes } \\
\hline & $\begin{array}{c}{[\mathrm{M}]} \\
\left(\mathrm{mol} \mathrm{L}^{-1}\right)\end{array}$ & $\begin{array}{c}10^{2}[\mathrm{I}] \\
\left(\mathrm{mol} \mathrm{L}^{-1}\right)\end{array}$ & $10^{-5} M_{\mathrm{w}}^{\mathrm{b}}$ & $M_{\mathrm{w}} / M_{\mathrm{n}}^{\mathrm{c}}$ & $\begin{array}{c}\text { Conversion }^{\mathrm{c}} \\
(\%)\end{array}$ & $\mathrm{DP}_{n}{ }^{\mathrm{b}}$ \\
\hline P7 & 0.159 & 0.850 & 1.73 & 1.18 & 90.2 & 54 \\
\hline P8 & 0.185 & 0.750 & 3.01 & 1.20 & 90.3 & 94 \\
\hline P9 & 0.205 & 0.667 & 3.62 & 1.26 & 80.8 & 113 \\
\hline P10 & 0.220 & 0.600 & 4.19 & 1.28 & 81.3 & 131 \\
\hline
\end{tabular}

${ }^{\text {a }}$ Polymerized in benzene initiated by AIBN at $60^{\circ} \mathrm{C}$ for $100 \mathrm{~h}$. ${ }^{\text {b }}$ Determined by LALLS-GPC. ${ }^{\mathrm{c}}$ Determined by GPC. 
Table V. Dilute-solution properties of double-cylinder-type copolymer brushes in benzene

\begin{tabular}{lcrcc}
\hline Code & $10^{-5} M_{\mathrm{w}}{ }^{\mathrm{a}}$ & $\mathrm{DP}_{n}$ & $\begin{array}{c}R_{\mathrm{g}}{ }^{\mathrm{b}} \\
(\mathrm{nm})\end{array}$ & $\begin{array}{c}R_{\mathrm{g}, \mathrm{c}} \\
(\mathrm{nm})\end{array}$ \\
\hline P11 & 0.68 & 19 & $6.9^{\mathrm{d}}$ & 3.2 \\
P12 & 0.86 & 24 & $7.6^{\mathrm{d}}$ & 3.3 \\
P13 & 1.37 & 38 & $8.6^{\mathrm{d}}$ & 3.3 \\
$\mathbf{P 1 4}$ & 1.91 & 53 & 12.1 & 3.3 \\
$\mathbf{P 1 5}$ & 2.02 & 56 & 12.5 & 3.3 \\
P16 & 2.88 & 30 & $8.2^{\mathrm{d}}$ & 5.1 \\
P17 & 7.30 & 76 & 13.2 & 5.0 \\
P18 & $11.0^{\mathrm{b}}$ & 115 & 23.1 & 5.4 \\
P19 & $5.07^{\mathrm{b}}$ & 158 & 16.0 & 3.2 \\
P20 & $13.1^{\mathrm{b}}$ & 410 & 27.0 & 3.5 \\
P21 & $32.5^{\mathrm{b}}$ & 1017 & 41.2 & 3.6 \\
\hline
\end{tabular}

${ }^{a}$ Determined by LALLS-GPC. ${ }^{b}$ Determined by static light scattering (SLS). ${ }^{\mathrm{C} C a l c u l a t e d}$ by cross-sectional Guinier's plot. ${ }^{\mathrm{d} C a l c u l a t e d}$ by Guinier's plot.

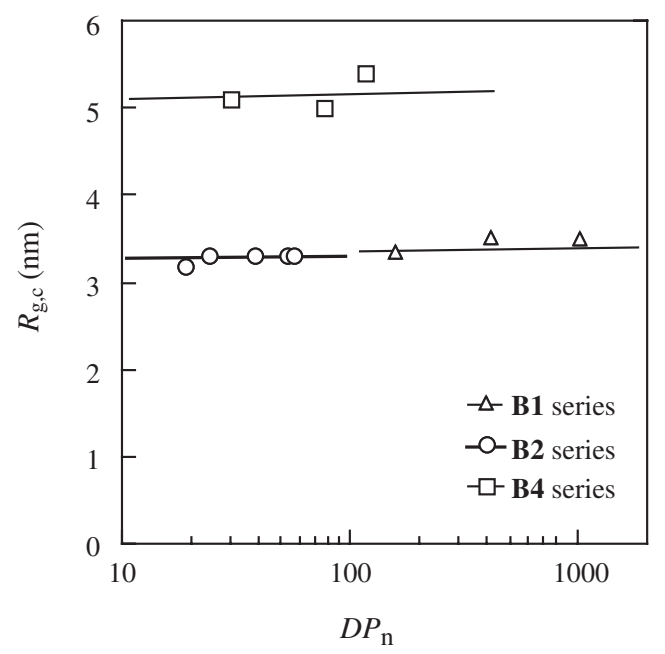

Figure 12. Relationship between the cross-sectional radius $R_{\mathrm{g}, \mathrm{c}}$ and $\mathrm{DP}_{n}$ of double-cylinder-type brushes for $\mathbf{B 1}, \mathbf{B 2}$, and B4 series as the starting diblock macromonomers.

fractionated by the precipitation method (benzenehexane system), to narrow the molecular weight distribution of copolymer brushes. $M_{\mathrm{w}}$ and $R_{\mathrm{g}}$ of doublecylinder-type brushes were derived from a Berry plot in benzene. In the case of small $\mathrm{DP}_{n}$ of the copolymer brushes, $R_{\mathrm{g}}$ was determined by Guinier's plots on SAXS. $R_{\mathrm{g}, \mathrm{c}}$ of the copolymer brushes was determined by cross-sectional Guinier's plots on SAXS. These physical values are listed in Table V. Figure 12 shows the relationship between $R_{\mathrm{g}, \mathrm{c}}$ and $\mathrm{DP}_{n}$ of double-cylinder-type brushes for the B1, B2, and B4 as the starting diblock macromonomers. The values of $R_{\mathrm{g}, \mathrm{c}}$ are almost constant in each series. This result means that the copolymer brushes exhibit the same radius, regardless of the aspect ratios.

In order to discuss geometrical anisotropy and in-

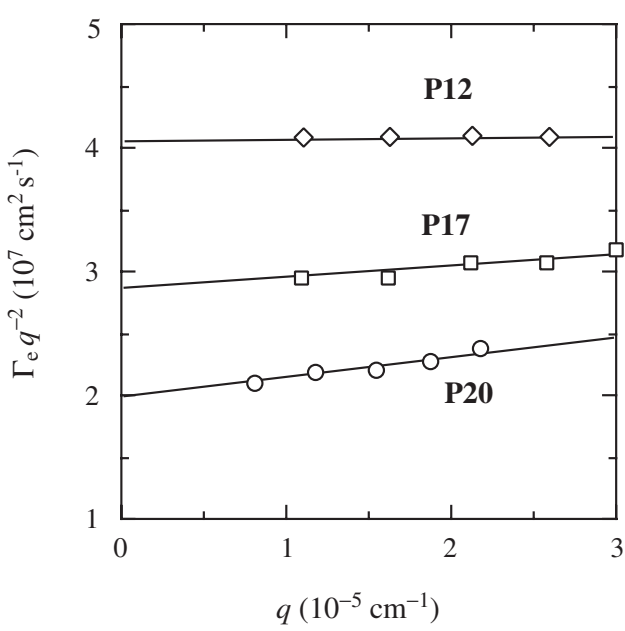

Figure 13. Angular dependence $\Gamma_{\mathrm{e}} q^{-2} v s . q$ for double-cylinder-type brushes P12, P17, and P20.

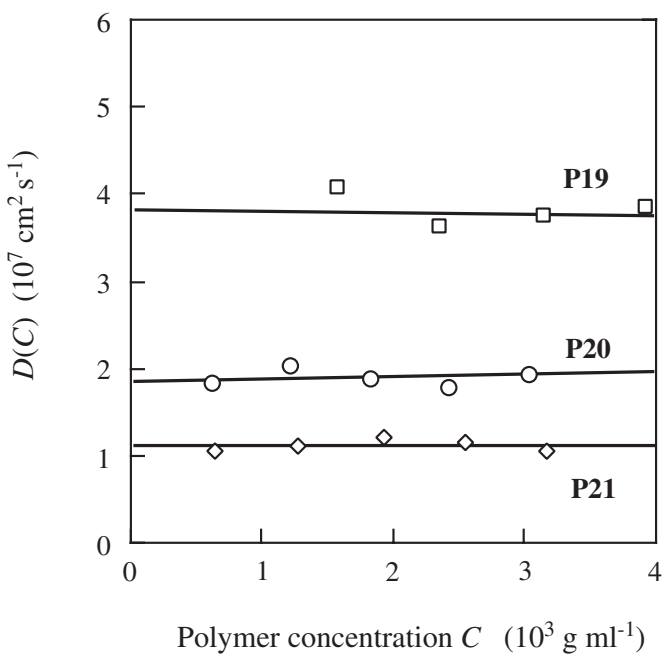

Figure 14. Plot of the translational diffusion coefficient $D(C)$ of double-cylinder-type brushes P19, P20, and P21.

termolecular interaction, they determined the translational diffusion coefficient $\left(D_{0}\right)$ of double-cylindertype brushes by means of DLS. The angular dependence of $\Gamma_{\mathrm{e}} q^{-2}\left(q R_{\mathrm{h}} \ll 1\right)$ for $\mathbf{P 1 2}, \mathbf{P 1 7}$, and $\mathbf{P 2 0}$ is shown in Figure 13. It was found that the observed data on the brush P12 fitted an almost flat line. This copolymer brush is composed of a short backbone $\left(\mathrm{DP}_{n}=24\right)$. It seems, therefore, that $\mathbf{P 1 2}$ takes the shape of a sphere or an ellipsoid in dilute solution. On the other hand, the copolymer brushes P17 and P20 shows an angular dependence. These copolymer brushes are composed of a long backbone length $\left(\mathrm{DP}_{n}=76\right.$ and 410$)$. It is concluded that the shape of the double-cylinder-type brushes changes from a sphere (or ellipsoid) to a rod-like cylinder in dilute solution with increasing $\mathrm{DP}_{n}$ of the copolymer brushes. Figure 14 shows the relationship between the transla- 
Table VI. Dilute-solution properties of cylinder brushes and double-cylinder-type brushes

\begin{tabular}{lccccr}
\hline Code & $10^{-5} M_{\mathrm{w}}$ & $\begin{array}{c}10^{5} A_{2}{ }^{\mathrm{a}} \\
\left(\mathrm{cm}^{3} \mathrm{~mol} \mathrm{~g}^{-2}\right)\end{array}$ & $\begin{array}{c}R_{\mathrm{g}}{ }^{\mathrm{b}} \\
(\mathrm{nm})\end{array}$ & $\begin{array}{c}10^{7} D_{0}{ }^{\mathrm{c}} \\
\left(\mathrm{cm}^{2} \mathrm{~s}^{-1}\right)\end{array}$ & $\begin{array}{r}R_{\mathrm{h}}{ }^{\mathrm{c}} \\
(\mathrm{nm})\end{array}$ \\
\hline P19 & 5.07 & 9.25 & 16.0 & 4.03 & 9.0 \\
P21 & 32.5 & 0.99 & 41.2 & 1.08 & 33.8 \\
P20 & 12.9 & 2.84 & 31.0 & 1.91 & 19.1 \\
P20C $^{\mathrm{d}}$ & 14.3 & 0.99 & 28.3 & 1.69 & 21.4 \\
P12 $^{\mathrm{P} 12 C}$ & 0.63 & 33.8 & 15.1 & 3.99 & 9.2 \\
P $^{\mathrm{d}}$ & 0.76 & 26.6 & 14.7 & 3.69 & 9.8 \\
\hline
\end{tabular}

${ }^{a}$ The second virial coefficient and determined by SLS. ${ }^{\mathrm{b}}$ Determined by SLS. ${ }^{\mathrm{c}}$ Determined by dynamic light scattering (DLS; cumulant method). ${ }^{\mathrm{d}}$ Cylinder brushes.

tional diffusion coefficient $D(C)$ and the polymer concentration $C$ for $\mathbf{P 1 9}\left(\mathrm{DP}_{n}=158\right), \mathbf{P 2 0}\left(\mathrm{DP}_{n}=410\right)$, and $\mathbf{P 2 1}\left(\mathrm{DP}_{n}=1017\right)$. Each $D(C)$ has an almost constant value in the range of $(0-5) \times 10^{-3} \mathrm{~g} \mathrm{~cm}^{-3}$ polymer concentration for all of the samples. This suggests that these double-cylinder-type brushes also form a unimolecular structure in such polymer concentrations. The translational diffusion coefficient $D_{0}$ can be estimated by extrapolation of the polymer concentration $C$ to zero. The values of $D_{0}$ and $R_{\mathrm{h}}$ are listed in Table VI. It was found that $D_{0}$ decreases with increasing DP in the same series. This is a reasonable result.

In order to obtain rigid cylinder brushes, the crosslinking reaction of internal P2VP domains of doublecylinder-type brushes (0.05-0.1 wt \%) was carried out with DIB (feed amounts $=50 \mathrm{~mol} \%$ based on P2VP units) in THF for $3 \mathrm{~d}$. Degree of quaternization (DQ) of the cylinder brushes was determined by Volhard's titration in benzene/water. The DQ of P20C and P12C was 38.1 and $43.6 \mathrm{~mol} \%$, respectively. Therefore, quaternized P2VP domains were regarded as hydrophilic domains. The dilute-solution properties of cylinder brushes are also listed in Table VI. Figure 15 shows the relationship between $D(C)$ and $C$ for P20, P20C, P12, and P12C. Each $D(C)$ for cylinder brushes (P20C and P12C) shows a constant value in the dilute solution region. This suggests that cylinder brushes form a unimolecular structure in dilute solution, such as copolymer brushes. Futhermore, it is noticed that the observed values of $D(C)$ for the cylinder brushes (P20C and P12C) are somewhat smaller than those for the corresponding double-cylinder-type brushes. That is to say, $R_{\mathrm{h}}$ of cylinder brushes increases compared with that of the corresponding doublecylinder-type brushes. The internal P2VP domains are converted into a hydrophilic gel, due to the cross-linking reaction (quaternization). Because of its high segment density and hydrophilic nature, the cylinder brush is drained only at periphery around cylinders. Similar behavior was also observed in a microgel. ${ }^{28}$ On the other hand, the $R_{\mathrm{g}}$ values of the cylinder

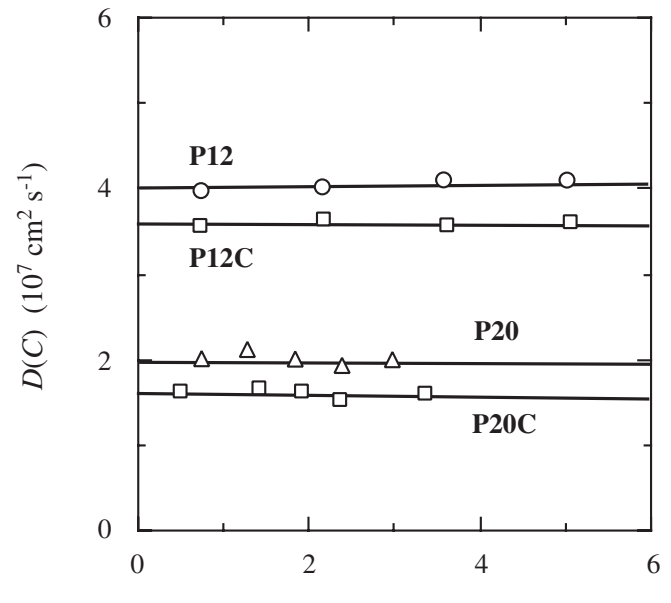

Polymer concentration $C \quad\left(10^{3} \mathrm{~g} \mathrm{ml}^{-1}\right)$

Figure 15. Plot of the translational diffusion coefficient $D(C)$ of cylinder brushes (P12C, P20C) and the corresponding doublecylinder-type brushes $(\mathbf{P 1 2}, \mathbf{P 2 0})$ against the polymer concentration $C$.

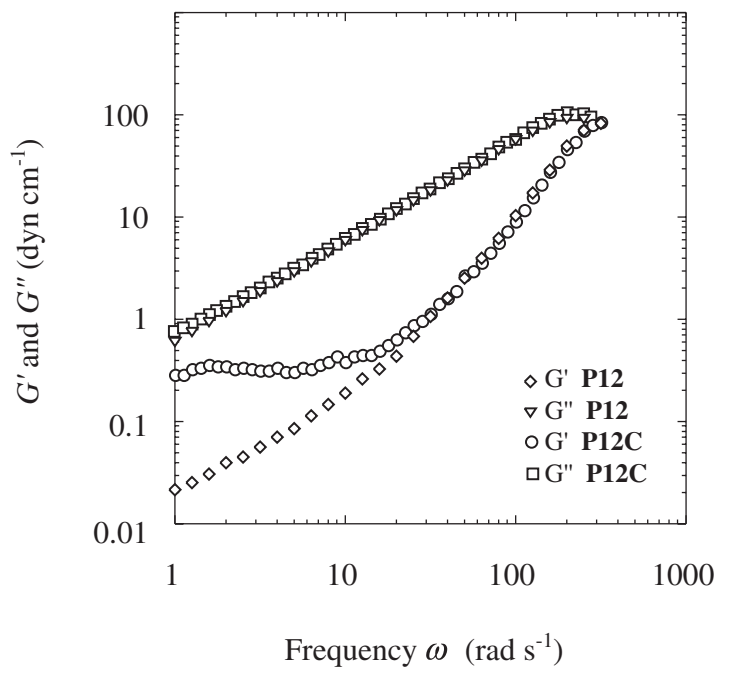

Figure 16. Relationship between the dynamic shear moduli (storage modulus $G^{\prime}$ and loss modulus $G^{\prime \prime}$ ) and angular frequency $\omega$ for P12C and P12 in $o$-xylene (20 wt \%).

brushes are also somewhat smaller than those of the corresponding double-cylinder-type brushes due to the compact nature by internal domain locking.

To investigate the viscoelasticity of a double-cylinder-type brush and cylinder brush, Ishizu et al. carried out the rheological measurement in a semi-dilute solution. ${ }^{26}$ Rheological properties of PS brushes have been investigated previously by Nanba et al. ${ }^{29}$ They discussed the bulk properties of multi-branched PSs by the master curve of the storage dynamic shear modulus $G^{\prime}$. Consequently, it was indicated that intermolecular chain entanglement might be strongly restricted in the polymer brush system due to the multi-branched structure of high branch density. Figure 16 shows the relationship between the dynamic shear moduli (stor- 


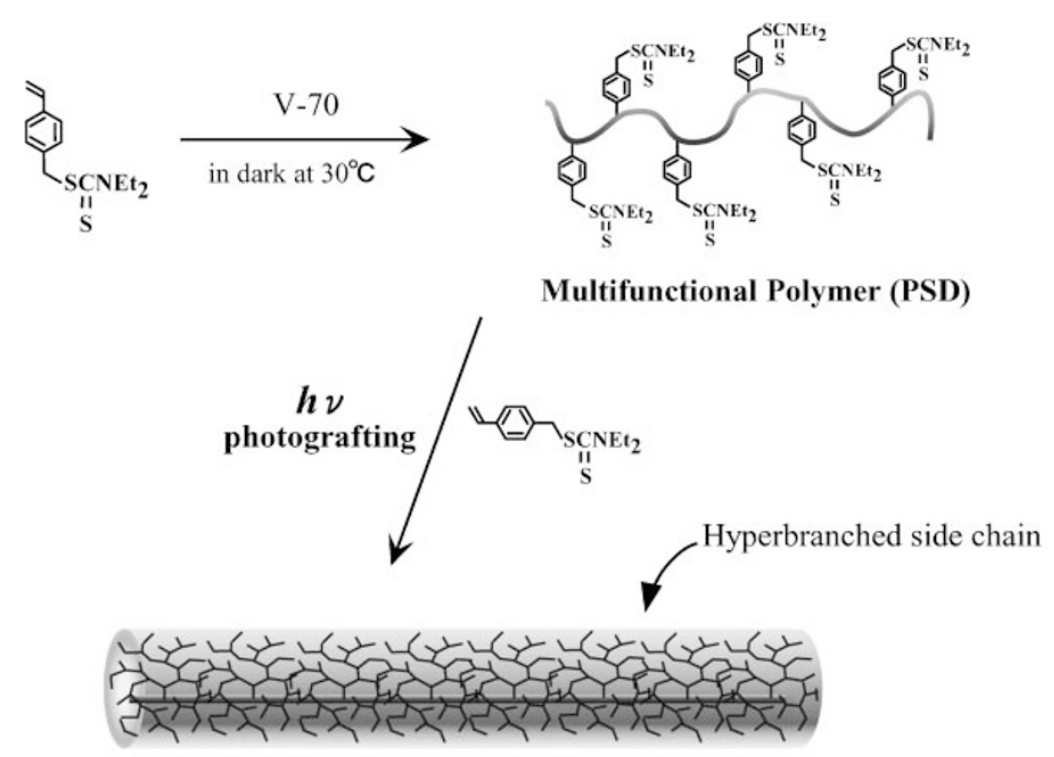

Nanocylinder

Scheme 3.

age modulus $G^{\prime}$ and loss modulus $G^{\prime \prime}$ ) and angular frequency $\omega$ for P12 and P12C in $o$-xylene $(20 \mathrm{wt} \%)$. The observed $G^{\prime}$ and $G^{\prime \prime}$ for the double-cylinder-type brush P12 fit on the same curve. However, $G^{\prime}$ for the cylinder brush $\mathbf{P 1 2}$ shows a clear plateau region at $\omega=10^{0}-2 \times 10^{1}\left(\mathrm{rad} \mathrm{s}^{-1}\right)$. In general, such a slow relaxation mode originates from entanglement effects. The P2VP block content of the polymerization products of $\mathbf{B 3}$ is $33 \mathrm{~mol} \%$. So, the cylindrical core of P12 sterically stabilized with a relatively thin thickness of the PMS shell parts. It seems that the cylinder brushes P12C leads to an intermolecular interaction among cross-linked cylindrical P2VP cores in semidilute solution. This fusion behavior was also observed in core-shell polymer microspheres consisting of an isotropic geometrical structure. ${ }^{30}$

Ishizu and Ohta have established the novel construction of rigid nanocylinders with hyperbranched polymer side groups via living radical mechanism. ${ }^{31}$ Scheme 3 shows the synthetic strategy of nanocylinders with hyperbranched side groups. Multifuctional PS (PSD) having $N, N$-diethyldithiocarbamate (DC) pendant groups which becomes the core in the final product serves as starting material. The anchor groups of this polymer are formed by hyperbranched structures by grafting of vinylbenzyl $N, N$-diethyldithiocarbamate (VBDC) inimer via living radical polymerization. Matyjaszewski's ${ }^{32}$ and Müller's groups ${ }^{33}$ have also synthesized double-cylinder-type brushes by the "grafting from" approach using ATRP. More recently, Ishizu and Kakinuma ${ }^{34}$ have established the preparation method of double-cylinder-type brushes by the similar "grafting from" photo-induced ATRP of
PSD with vinyl monomers [first monomer, $t$-butyl methacrylate (BMA); second monomer, styrene or MMA] (see Scheme 4). A copper complex, $\mathrm{CuCl} /$ bipyridine (bpy) activated reversibly the domant polymer chains via a DC transfer reaction such as $\mathrm{CuCl}(\mathrm{DC}) /$ bpy, and it was dynamic equilibrium which was responsible for the controlled behavior of the polymerizations of BMA and MMA. They have also prepared a functionalized macroinimer by DCmediated living free-radical polymerization. ${ }^{35}$ The Living free-radical copolymerization of the mixture of VBDC, maleic anhydride (MA) and an excess of styrene was studied in THF under UV irradiation. The key to this synthesis was the possibility of initial formation of styrene/MA sequence units by the preferential and controlled alternating copolymerization. As a result, the propagating copolymer radicals always proceeded with homopolymerization of $1: 1$ complexes formed between the electron donor and acceptor monomers. Further polymerization involved growth of a PS block. These functionalized macroinimers can be utilized for the synthesis of double-cylinder-type brushes by homopolymerization. On the other hand, Schmidt et al. have reported the polymerization method of macromonomer to cylindrical brushes initiated by organolanthanides. ${ }^{36}$ The polydispersity $M_{\mathrm{w}} / M_{\mathrm{n}}$ of the high molar mass samples lie in the regime $\approx 2$, which is significantly smaller than obtained by free-radical polymerization. This method will be the most useful procedure for the architecture of a well-defined double-cylinder-type brush.

The molecular wires in electronic nanodevices were prepared by forming a linear array of gold clusters ${ }^{37}$ 
Architecture of Multi-Component Copolymer Brushes

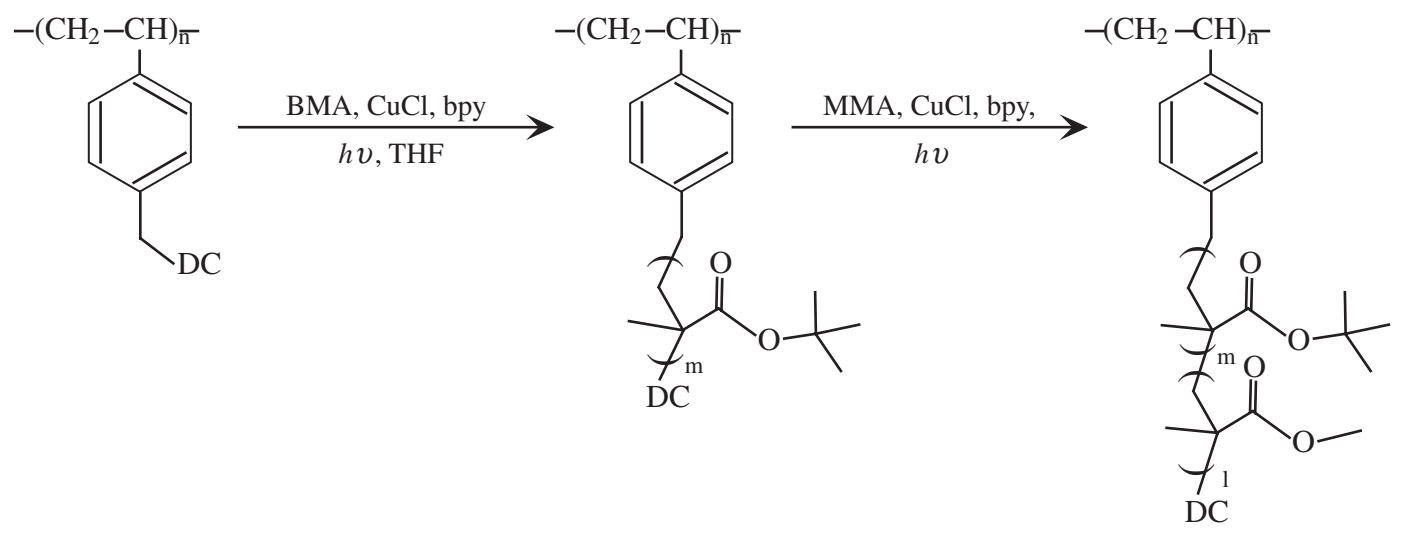

PSD

Polymer brush

Double-cylinder-type brush

Scheme 4.

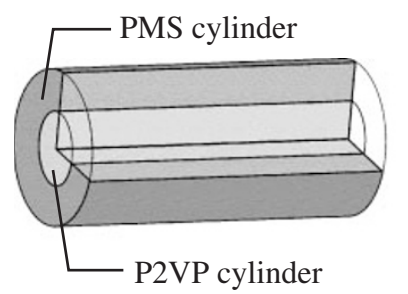

Double-cylinder type polymer brush

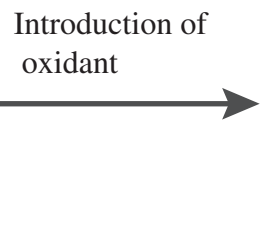

Copolymer brush/ $\mathrm{Cu}^{2+}$ ionic complex

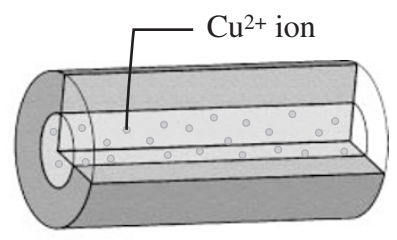

Oxidation polymerization of pyrrole

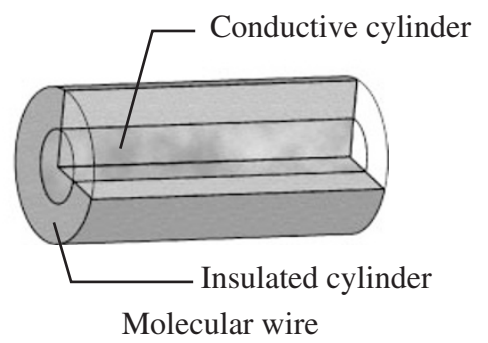

Figure 17. Modification steps for encapsulation of polypyrrole into double-cylinder-type copolymer brush.

or conducting polypyrroles (PPy) ${ }^{38}$ with an internal core of double-cylinder-type brushes as templates, whereas the outer cylinder parts play the role of an insulator. Modification steps for the encapsulation of PPy are shown in Figure $17 .{ }^{38}$ The characteristics of PMS-block-P2VP double-cylinder-type brush $\mathbf{P 2 2}$ employed in this work were as follows: $M_{\mathrm{w}}=1.37 \times$ $10^{6}, \mathrm{DP}_{n}=460$, P2VP block $8 \mathrm{~mol} \%$. This copolymer brush formed a single macromolecule even in good solvent such as benzene, due to crowded side chains. $\mathrm{Cu}^{2+}$ ions (oxidant) were introduced into internal P2VP cylindrical domains by complexation based on the pyridine nitrogen interacting with metal ions. Encapsulation of PPys was performed by the oxidation polymerization of double-cylinder-type brushes complexed with such an oxidizing agent being added to a mixture of pyrrole and water vapor. Figure 18a shows the hydrodynamic diameter distribution of the polymerization product $\mathbf{P 2 2} \mathbf{W}$ in benzene. The size distribution profile appears unimodal at around 30 $\mathrm{nm}$. It indicates that the encapsulation product of PPy forms a single macromolecule in solution. To make clear the double-cylinder structure of encapsulation material of PPy, the GPC measurements of P22W and $\mathbf{P 2 2}$ equipped with RI and UV (characteristic absorption of PPy at $336 \mathrm{~nm}$ ) double detectors were carried out in THF as the eluent (see Figure 18b). The GPC elution pattern of P22W is identical with that of the copolymer brush P22 in the RI monitor. However, it is found from the UV monitor that the intensity of UV absorption for $\mathbf{P 2 2} \mathbf{W}$ appears strong as well as the elution pattern observed in the RI monitor. Internal PPy phases are stabilized sterically by highly branched PMS chains in solution. 

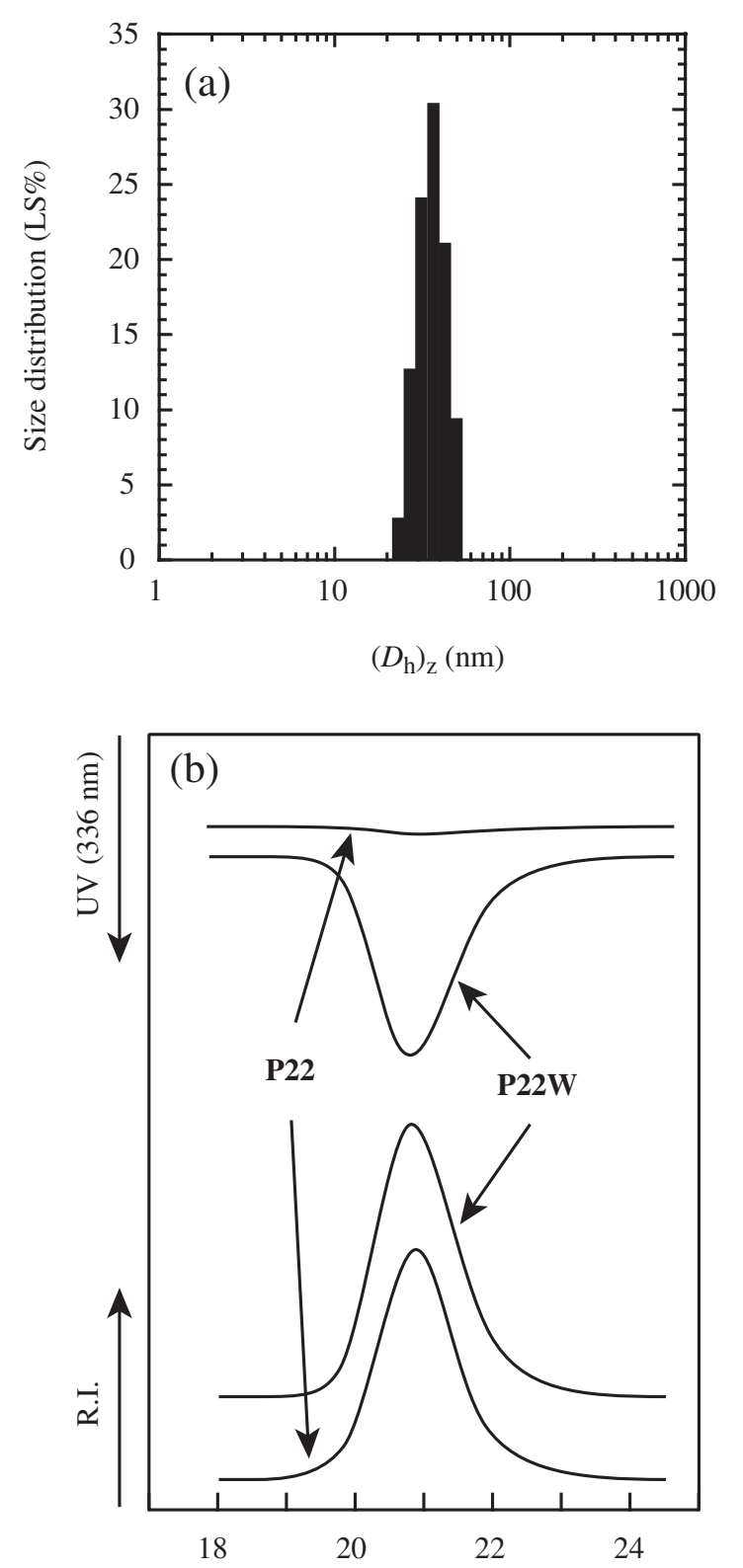

Figure 18. Hydrodynamic diameter $\left(D_{\mathrm{h}}\right)$ distribution of P22W (a) and GPC profiles of P22W and copolymer brush P22 (b).

\section{BLOCK-TYPE COPOLYMER BRUSHES}

ATRP was applied to the synthesis of AB-type brush-block-brush amphiphilic copolymers (see
Figure 1c). ${ }^{39}$ The synthetic scheme is shown in Scheme 5 The procedure included the following steps: (1) ATRP of methacryloyl-terminated PEO (PEO-MC) gave well-defined PEO brush macroinitiator (formula $\mathrm{P}\left[(\mathrm{EO})_{40} \mathrm{Br}\right]$ ), (2) subsequent ATRP of 2hydroxyethyl methacrylate (HEMA) with this brush macroinitiator provided PEO brush-block-PHEMA (brush-block-coil) diblock copolymers (formula $\left.\left.\mathrm{P}\left[(\mathrm{EO})_{40}-b \text {-(HEMA }\right)_{30}\right]\right)$, (3) esterification of the pendant hydroxy groups of PHEMA block with 2-bromoisobutyryl bromide yielded a block-type polyinitiators, brush-block-poly(2-(2-bromoisobutyryloxy)ethyl methacrylate) (PBIEM) (number of initiation sites per PHEMA block, $N_{\mathrm{BIB}}=14$ ), (4) ATRP of HEMA using brush-block-PBIEM as polyinitiator provided AB-type brush-block-brush amphiphilic copolymer P23. Table VII lists the characteristics of AB-type PEO brush-block-PHEMA brush copolymer brush P23. The $\mathrm{DP}_{n}$ of the PHEMA side chain was calculated from both $M_{\mathrm{n}}$ of copolymer brush and polyinitiator precursor, assuming that all of the initiation sites on the PBIEM block led to propagation of HEMA. This sample $\mathbf{P 2 3}$ has in total only 70 main chain units $\left(\mathrm{DP}_{n, \mathrm{PMMA}}+\mathrm{DP}_{n, \mathrm{PHEMA}}\right)$ as compared to 45 (PEO) and 21 (PHEMA) side chain units, respectively. In addition the grafting density of PHEMA is quite low, i.e., one side chain per two main chains repeat units. Therefore, the aspect ratio of AB-type copolymer brush seems not so long.

This copolymer brush showed a weak angular dependence of $\Gamma_{\mathrm{e}} q^{-2}$ on $q$ in benzene, and the mutual diffusion coefficient $D(C)$ has an almost constant value $\left(D_{0}=7.4 \times 10^{-7} \mathrm{~cm}^{2} \mathrm{~s}^{-1}, R_{\mathrm{h}}=5.4 \mathrm{~nm}\right)$ in the range $4-15 \mathrm{mg} \mathrm{mL}^{-1}$ of polymer concentration. The copolymer brush P23 is molecularly dissolved in the dilute solution. The values of $R_{\mathrm{g}}$ and $R_{\mathrm{g}, \mathrm{c}}$ of copolymer brush $\mathbf{P 2 3}$ were estimated from the corresponding slop of Guinier's plots at the small-angle region $(q R \ll 1)$. These physical values also list in Table VII. The $R_{\mathrm{g}} / R_{\mathrm{h}}$ value (calculated as 1.4 from Table VII) on $\mathbf{P 2 3}$ indicates relatively compact shape.

Assuming a polydisperse rodlike shape (P23; $\left.M_{\mathrm{w}} / M_{\mathrm{n}}=1.78\right)$ and neglecting the cross-sectional dimension, $R_{\mathrm{g}}$ is given by the relation

Table VII. Characteristics and solution properties of AB-type PEO brush-block-PHEMA brush copolymer ${ }^{\mathrm{a}}$

\begin{tabular}{ccccccccc}
\hline Code & $10^{-5} M_{\mathrm{w}}{ }^{\mathrm{b}}$ & $M_{\mathrm{w}} / M_{\mathrm{n}}{ }^{\mathrm{c}}$ & $\begin{array}{c}\text { Grafting efficiency } \\
\text { of HEMA }(\%)\end{array}$ & $\begin{array}{c}\mathrm{DP}_{n} \text { of PHEMA } \\
\text { side chain }^{\mathrm{d}}\end{array}$ & $\begin{array}{c}10^{7} D_{0}{ }^{\mathrm{e}} \\
\left(\mathrm{cm}^{2} \mathrm{~s}^{-1}\right)\end{array}$ & $\begin{array}{c}R_{\mathrm{h}}{ }^{\mathrm{e}} \\
(\mathrm{nm})\end{array}$ & $\begin{array}{c}R_{\mathrm{g}}{ }^{\mathrm{f}} \\
(\mathrm{nm})\end{array}$ & $\begin{array}{c}R_{\mathrm{g}, \mathrm{c}}{ }^{\mathrm{f}} \\
(\mathrm{nm})\end{array}$ \\
\hline $\mathbf{P 2 3}$ & 2.17 & 1.78 & 44 & 21 & 7.4 & 5.4 & 7.5 & 3.9 \\
\hline
\end{tabular}

a $50 \mathrm{wt} \%$ of HEMA aqueous solution was polymerized at room temperature for $8 \mathrm{~h}$ under the conditions: [HEMA]:[PEO brush-block-PBIEM polyinitiator]:[CuCl]:[bipyridine] $=50: 1: 1: 2$. ${ }^{\mathrm{b}}$ Determined by $\mathrm{SLS}$ in chloroform at $25^{\circ} \mathrm{C}$. ${ }^{\mathrm{c}}$ Determined by GPC-LALLS in DMF as eluent at $40{ }^{\circ} \mathrm{C}$. ${ }^{\mathrm{d}}$ Calculated from both $M_{\mathrm{n}}$ of copolymer brush and polyinitiator precursor. ${ }^{\text {e }}$ Determined by DLS in chloroform at $25^{\circ} \mathrm{C}$. ${ }^{\mathrm{f}}$ Determined by SAXS in chloroform using Guinier's plots. 
Architecture of Multi-Component Copolymer Brushes

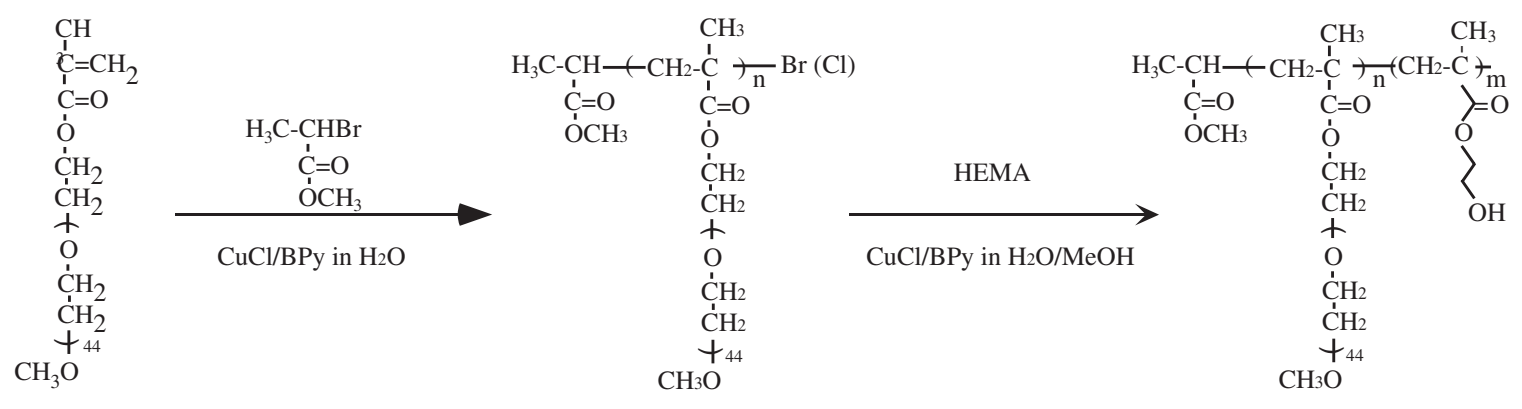

PEO-MC

PEO brush macroinitiator

PEO brush-block-PHEMA

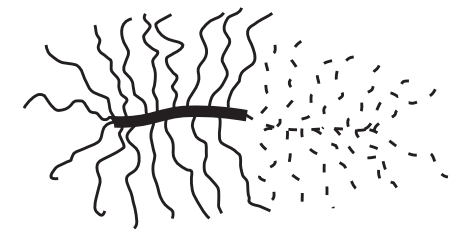

Block-Type Brush

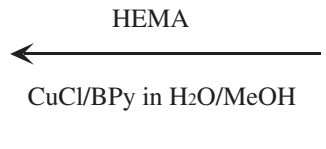

$$
\left(L_{\mathrm{w}} / L_{\mathrm{n}}=2\right)
$$

Equation 3 allows evaluating the rod length as $L_{\mathrm{w}}=15 \mathrm{~nm}$. Since the cross-sectional diameter $d$ is estimated to be $11.0 \mathrm{~nm}$, the aspect ratio $L_{\mathrm{w}} / d(1.36)$ is significantly smaller than 2.5 . Accordingly, the prepared AB-type sample is much more similar to Janustype micelles ${ }^{40}$

The aggregation behaviors of such Janus-type amphiphilic copolymer brush $\mathbf{P 2 3}$ were investigated in an aqueous media. ${ }^{41}$ Figure 19a shows the hydrodynamic diameter $\left(D_{\mathrm{h}}\right)$ distribution of $\mathbf{P 2 3}$ in an aqueous solution $\left(2 \times 10^{-2} \mathrm{mg} \mathrm{mL}^{-1}\right)$ by DLS measurement. Polymer solution showed turbidity but no precipitates were observed. An aqueous solution of PEO brushes was homogeneous at the same polymer concentration. Water is a good solvent for PEO and somewhat poor for PHEMA. Single peak is observed at $200 \mathrm{~nm}$. This peak appearing at the larger $D_{\mathrm{h}}$ suggests the presence of aggregates in the system. Figure 19b shows a typical FE-SEM photograph of the aggregation product of P23 $\left(3 \times 10^{-3} \mathrm{mg} \mathrm{mL}^{-1}\right.$ of aqueous solution was placed onto a glass plate and spin coating was conduced immediately at $3000 \mathrm{rpm}$ for $5 \mathrm{~min}$ ). The texture shows the existence of large particles (observed
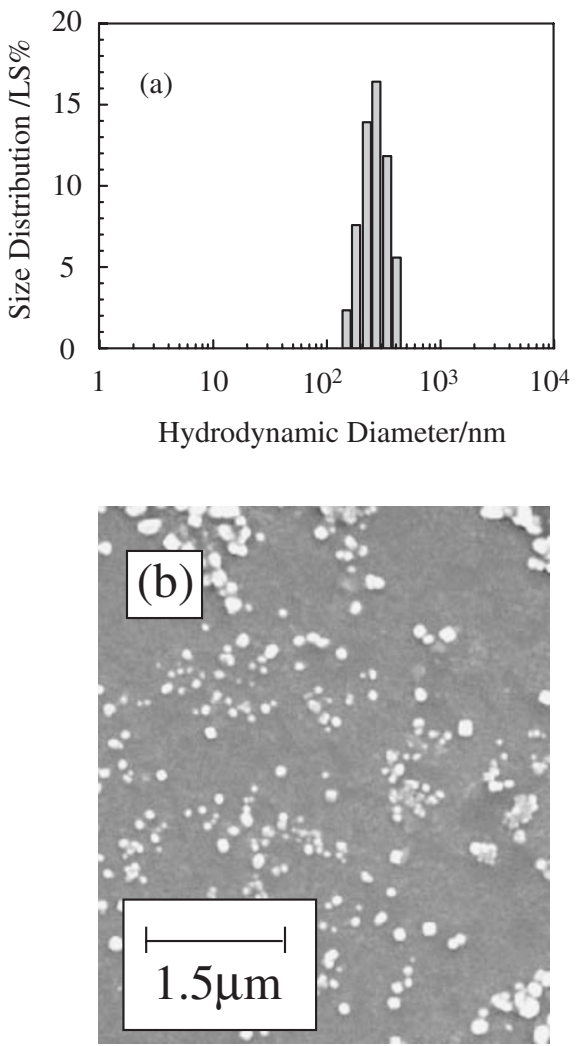

Figure 19. Hydrodynamic diameter distribution of block-type copolymer brush $\mathbf{P 2 3}$ in water $\left(2 \times 10^{-2} \mathrm{mg} \mathrm{mL}^{-1}\right)$ (a) and FESEM photograph of $\mathbf{P 2 3}$ (prepared from $3 \times 10^{-3} \mathrm{mg} \mathrm{mL}^{-1}$ aqueous solution) (b). 


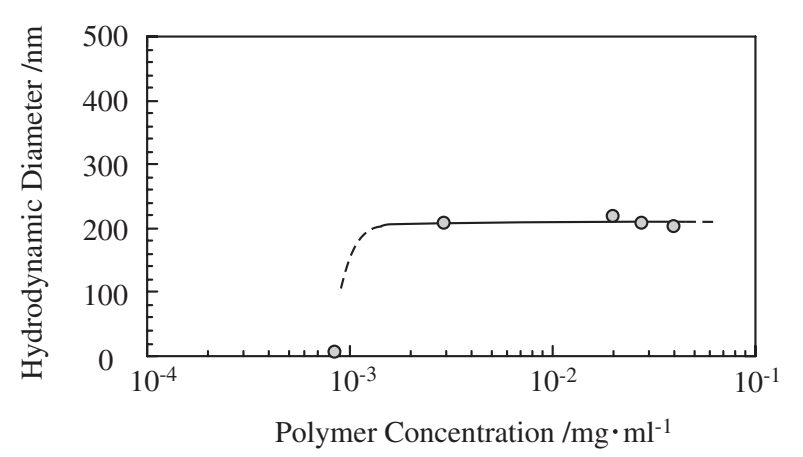

Figure 20. Polymer concentration dependence on the aggregate formation for block-type copolymer brush $\mathbf{P 2 3}$ in water.

diameter; ca. $190 \mathrm{~nm}$ ). Figure 20 shows the polymer concentration dependence on the aggregate formation for P23. This copolymer brush forms uniform aggregates beyond $10^{-3}$ until $0.6 \mathrm{mg} \mathrm{mL}^{-1}$. However, these aggregates precipitated beyond $0.6 \mathrm{mg} \mathrm{mL}^{-1}$. A Janus-type ellipsoid of a length $15 \mathrm{~nm}$ formed a spherical aggregate of a diameter $200 \mathrm{~nm}$. The aggregation mechanism can be speculated as follows. Less hydrophilic PHEMA domains lead to aggregation with each other in an aqueous solution, and PHEMA core-PEO shell type spherical particles may be formed in the first stage. Subsequently, such PEO shells lead to fusion with PEO domains of Janus-type brushes. By repeating these aggregation processes, large multiplephase particles having "onion-like" morphology (supermicelle) are formed as sketched in Figure 21. These uniform particles (diameter $200 \mathrm{~nm}$ ) are stabilized sterically by densely grafted PEO chains in the range $10^{-3}-0.6 \mathrm{mg} \mathrm{mL}^{-1}$ polymer concentration.

As mentioned in the former section, hierarchical generation from small rods to large rods was observed in self-assembly process of prototype copolymer brushes. Thus, the trend of aggregation behavior for Janus-type copolymer brushes is very different from that for prototype copolymer brushes. Qin et al. also reported the block-type copolymer brushes via ATRP route. ${ }^{42}$ These copolymer brushes may find a number of application in nanotechnology.

\section{CONCLUSIONS}

The prototype copolymer brushes were synthesized by alternating free-radical copolymerizations of PSVB or PPO-VB with a PEO-MC/ $\mathrm{SnCl}_{4}$ complex. It was found from their dilute-solution properties that such copolymer brushes were molecularly dissolved in a dilute solution and took geometrically anisotropic conformation such as cylinder with increasing aspect ratio. In self-assembly process of PS/PEO prototype brushes in water, hierarchical generations from small rods to large rods were observed, because copolymer brushes exhibited phase-separated hydrophobic/hydrophilic domains. On the other hand, PPO/PEO prototype copolymer brushes formed the cascade, i.e., tree-like aggregates by 3-D generation, because hydrophobicity for PPO domains was weaker than that for PS domains in water.

The PS/PEO prototype copolymer brushes were converted into PSS/PEO brushes (anionic/nonionic polyelectrolyte prototype) by sulfonation. The electrostatic interactions of charged prototype brushes with cationic linear polyelectrolyte P4VPQ were investigated by FE-SEM as parameters of blend ratios and polymer concentration. Textures of FE-SEM photographs indicated the flux of large rigid rods or a single rod $($ diameter $=c a .130 \mathrm{~nm})$. This rod diameter was too large, under assumption that single PSS/PEO brush bind with P4VPQ by electrostatic interaction. It could be speculated that there were several P4VPQ chains inside the aggregates and these semiflexible P4VPQ chains changed to stretched conformation by electrostatic interaction during binding process.

Free-radical polymerization of diblock macromonomers and "grafting from" approach using (photo-induced) ATRP provided the double-cylinder-type copolymer brushes. These types also formed a single macromolecule in solution. The shape of these copolymer brushes changed from a sphere (or ellipsoid) to a rod-like cylinder in dilute solution with increasing $\mathrm{DP}_{n}$ of the copolymer brushes. The molecular wires in
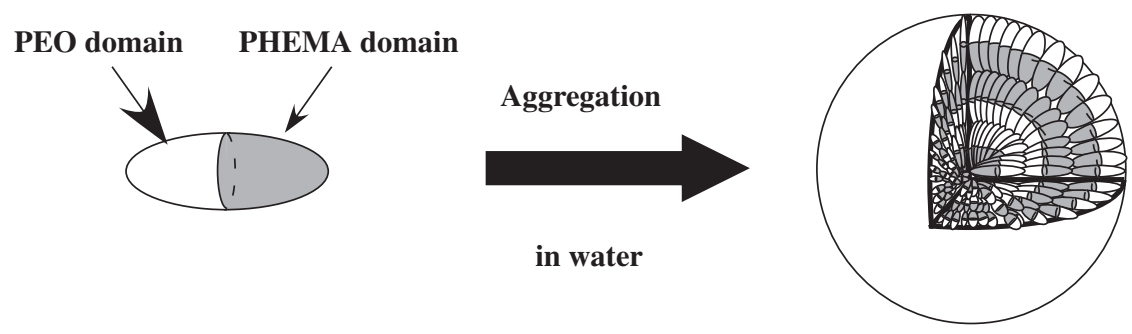

Janus-Type Brush

Particle with Onion-like Morphology

Figure 21. Illustration in aggregation process of Janus-type copolymer brushes. 
electronic nanodevices could be prepared by forming the conducting PPy with an internal core of doublecylinder-type brushes as templates, whereas the outer cylinder parts play the role of an insulator.

The ATRP technique was applied to the synthesis of AB-type PEO brush-block-PHEMA brush amphiphilic copolymers. It was found from SLS, DLS, and SAXS measurements that this brush exhibited a spherical or slightly ellipsoid rather than a cylindrical shape due to short aspect ratio. Especially, AB-type amphiphilic copolymer brush (aspect ratio $L_{\mathrm{w}} / d=$ 1.36) was much more similar to Janus-type micelles. A Janus-type brushes formed large multi-phase particle aggregates having onion-like morphology (supermicelle). The trend of aggregation behavior for Janus-type copolymer brushes was very different from that for prototype copolymer brushes.

\section{REFERENCES}

1. M. Wintermantel, K. Fischer, M. Gerie, R. Ries, M. Schmidt, K. Kajiwara, H. Urakawa, and I. Wataoka, Angew. Chem., Int. Ed., 34, 1472 (1995).

2. M. Wintermantel, M. Gerie, K. Fischer, M. Schmidt, I. Wataoka, H. Urakawa, K. Kajiwara, and Y. Tsukahara, Macromolecules, 29, 978 (1996).

3. M. Wintermantel, M. Schmidt, Y. Tsukahara, K. Kajiwara, and S. Kohjiya, Macromol. Rapid Commun., 15, 279 (1994).

4. Y. Tsukahara, S. Kohjiya, K. Tsutsumi, and Y. Okamoto, Macromolecules, 27, 1662 (1994).

5. N. Nemoto, M. Nagai, A. Koike, and D. Okada, Macromolecules, 28, 3854 (1995).

6. I. Wataoka, H. Urakawa, K. Kajiwara, M. Schmidt, and M. Wintermantel, Polym. Int., 44, 365 (1997).

7. K. Terao, Y. Nakamura, and T. Norisuye, Macromolecules, 32, 711 (1999).

8. S. Kawaguchi, G. Imai, J. Suzuki, A. Miyahara, T. Kitano, and K. Ito, Polymer, 38, 2885 (1997).

9. S. Kawaguchi, H. Matsumoto, H. Iriany, and K. Ito, Polym. Prepr. Jpn., 47, 1694 (1998).

10. K. Ishizu, T. Ikemoto, and A. Ichimura, Polymer, 40, 3147 (1999).

11. K. Ishizu, T. Ikemoto, and A. Ichimura, Sen-i Gakkaishi, 54, 502 (1998).

12. K. Ishizu, T. Hosokawa, and K. Tsubaki, Eur. Polym. J., 36, 1333 (2000).

13. K. Ishizu and K. Sunahara, Polymer, 36, 4135 (1995).

14. K. Ishizu and X. X. Shen, Polymer, 40, 3251 (1999).

15. K. Ishizu, X. X. Shen, and K. Tsubaki, Polymer, 41, 2053
(2000).

16. K. Tsubaki, H. Kobayashi, J. Satoh, and K. Ishizu, J. Colloid Interface Sci., 241, 275 (2001).

17. K. Ishizu, N. Sawada, J. Satoh, and A. Sogabe, J. Mater. Sci. Lett., 22, 1219 (2003).

18. M. Antonietti, W. Bremser, and M. Schmidt, Macromolecules, 23, 3796 (1990).

19. M. Schmidt, Macromolecule, 17, 553 (1984).

20. Z. Bo, J. P. Rabe, and A. D. Schlüter, Angew. Chem., Int. Ed., 38, 2370 (1999).

21. J. Frahn, B. Karakaya, A. Schafer, and A. D. Schlüter, Tetrahedron, 53, 15459 (1997).

22. K. Ishizu, K. Toyoda, T. Furukawa, and A. Sogabe, Macromolecule, 37, 3954 (2004).

23. T. Imae, T. Hirota, K. Funayama, K. Aoi, and M. Okada, J. Colloid Interface Sci., 263, 306 (2003).

24. B. Zhang, S. Zhang, L. Okrasa, T. Pakula, T. Stephan, and M. Schmidt, Polymer, 45, 4009 (2004).

25. K. Ishizu, K. Tsubaki, and T. Ono, Polymer, 39, 2935 (1998).

26. K. Tsubaki and K. Ishizu, Polymer, 42, 8387 (2001).

27. K. Ishizu, K. Shimomura, R. Saito, and T. Fukutomi, J. Polym. Sci., Polym. Chem. Ed., 29, 607 (1991).

28. S. Mossmer, J. P. Möller, T. Aberle, J. Schmidt, and W. Barchard, Macromolecules, 33, 4791 (2000).

29. S. Nanba, Y. Tsukahara, K. Kaeriyama, K. Okamoto, and M. Takahashi, Polymer, 41, 5165 (2000).

30. K. Ishizu, F. Naruse, and R. Saito, Polymer, 35, 2329 (1994).

31. K. Ishizu and Y. Ohta, J. Mater. Sci. Lett., 22, 647 (2003).

32. H. G. Borner, K. Beers, K. Matyjaszewski, S. S. Sheiko, and M. Möller, Macromolecules, 34, 4375 (2001).

33. G. Cheng, A. Boker, M. Zhang, G. Kraush, and A. H. E. Müller, Macromolecules, 34, 6883 (2001).

34. K. Ishizu and H. Kakinuma, J. Polym. Sci., Part A: Polym. Chem., in press.

35. K. Ishizu, H. Kakinuma, and J. Park, J. Polym. Sci., Part A: Polym. Chem., 42, 3644 (2004).

36. M. W. Neiser, J. Okuda, and M. Schmidt, Macromolecules, 36, 5437 (2003).

37. R. Djalali, S.-Y. Li, and M. Schmidt, Macromolecules, 35, 4282 (2002).

38. K. Ishizu, K. Tsubaki, and S. Uchida, Macromolecules, 35, 10193 (2002).

39. K. Ishizu, J. Satoh, and A. Sogabe, J. Colloid Interface Sci., 274, 472 (2004).

40. A. Mueller and D. F. O'Brien, Chem. Rev., 102, 727 (2002).

41. K. Ishisu, J. Satoh, and K. Toyoda, J. Mater. Sci., 39, 4295 (2004).

42. K. Qin, K. Matyjaszewski, H. Xu, and S. S. Sheiko, Macromolecules, 36, 605 (2003). 


\section{K. ISHIZU}

Koji Ishizu was born in Shimane Prefecture, Japan, in 1946. He received his M. S. and Ph. D. degrees in Polymer Chemistry from Tokyo Institute of Technology, 1970 and 1975, respectively. In 1981, he joined the Department of Chemistry, University of Arizona in Tucson, AZ (under the guidance of the late Prof. Carl S. Marvel). He was promoted to Associate Professor in 1990 and to Full Professor in 1995 at Tokyo Institute of Technology. Throughout his career he has been engaged in polymer science and, particularly, in the architecture of nanostructured and nanopatterned polymers. 